\title{
Heterogeneous Behavior of the Campotosto Normal Fault (Central Italy) Imaged by InSAR GPS and Strong-Motion Data: Insights from the 18 January 2017 Events
}

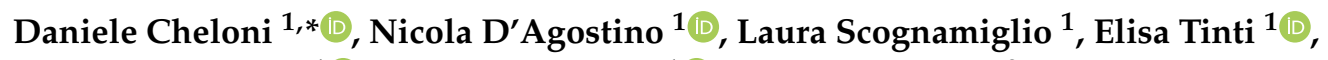 \\ Christian Bignami ${ }^{1}$ (D), Antonio Avallone ${ }^{1}{ }^{\mathbb{D}}$, Roberta Giuliani ${ }^{2}$, Stefano Calcaterra ${ }^{3}$, \\ Piera Gambino ${ }^{3}$ and Maurizio Mattone ${ }^{2}$ \\ 1 Istituto Nazionale di Geofisica e Vulcanologia (INGV), 00143 Rome, Italy; nicola.dagostino@ingv.it (N.D.); \\ laura.scognamiglio@ingv.it (L.S.); elisa.tinti@ingv.it (E.T.); christian.bignami@ingv.it (C.B.); \\ antonio.avallone@ingv.it (A.A.) \\ 2 Dipartimento della Protezione Civile, Via Vitorchiano 4, 00189 Rome, Italy; \\ roberta.giuliani@protezionecivile.it (R.G.); maurizio.mattone@protezionecivile.it (M.M.) \\ 3 Istituto Superiore per la Protezione e la Ricerca Ambientale, Via Vitaliano Brancati 48, 00144 Rome, Italy; \\ stefano.calcaterra@isprambiente.it (S.C.); piera.gambino@isprambiente.it (P.G.) \\ * Correspondence: daniele.cheloni@ingv.it
}

Received: 13 May 2019; Accepted: 18 June 2019; Published: 22 June 2019

\begin{abstract}
On 18 January 2017, the 2016-2017 central Italy seismic sequence reached the Campotosto area with four events with magnitude larger than 5 in three hours (major event $M_{W}$ 5.5). To study the slip behavior on the causative fault/faults we followed two different methodologies: (1) we use Interferometric Synthetic Aperture Radar (InSAR) interferograms (Sentinel-1 satellites) and Global Positioning System (GPS) coseismic displacements to constrain the fault geometry and the cumulative slip distribution; (2) we invert near-source strong-motion, high-sampling-rate GPS waveforms, and high-rate GPS-derived static offsets to retrieve the rupture history of the two largest events. The geodetic inversion shows that the earthquake sequence occurred along the southern segment of the SW-dipping Mts. Laga normal fault system with an average slip of about $40 \mathrm{~cm}$ and an estimated cumulative geodetic moment of $9.29 \times 10^{17} \mathrm{Nm}$ (equivalent to a $\mathrm{M}_{\mathrm{W}} \sim 6$ ). This latter estimate is larger than the cumulative seismic moment of all the events, with $\mathrm{M}_{\mathrm{W}}>4$ which occurred in the corresponding time interval, suggesting that a fraction $(\sim 35 \%)$ of the overall deformation imaged by InSAR and GPS may have been released aseismically. Geodetic and seismological data agree with the geological information pointing out the Campotosto fault segment as the causative structure of the main shocks. The position of the hypocenters supports the evidence of an up-dip and northwestward rupture directivity during the major shocks of the sequence for both static and kinematic inferred slip models. The activated two main slip patches are characterized by rise time and peak slip velocity in the ranges $0.7-1.1 \mathrm{~s}$ and $2.3-3.2 \mathrm{~km} / \mathrm{s}$, respectively, and by $\sim 35-50 \mathrm{~cm}$ of slip mainly concentrated in the shallower northern part of causative fault. Our results show that shallow slip (depth $<5 \mathrm{~km}$ ) is required by the geodetic and seismological observations and that the inferred slip distribution is complementary with respect to the previous April 2009 seismic sequence affecting the southern half of the Campotosto fault. The recent moderate strain-release episodes (multiple M 5-5.5 earthquakes) and the paleoseismological evidence of surface-rupturing events ( $\mathrm{M} \sim 6.5$ ) suggests therefore a heterogeneous behavior of the Campotosto fault.
\end{abstract}

Keywords: InSAR; Sentinel-1; GPS; high-rate GPS; strong-motion; normal faulting earthquake; continental tectonic; source modeling; central Italy; kinematic inversion; seismic cycle 


\section{Introduction}

In recent decades, the increasing availability of geodetic measurements such as short repeat-time Interferometric Synthetic Aperture Radar (InSAR) measurements and continuous Global Positioning System (GPS) observations in combination with seismological data has revealed that slip-on tectonic faults can occur in a continuous spectrum of modes, including seismic (earthquakes) and aseismic (e.g., creep events, afterslip, slow slips) events of different extent, duration, and temporal evolution (e.g., [1-7]). Defining the seismogenic behavior of active faults, i.e., the way in which a fault releases the accrued tectonic strain is a crucial question in seismotectonics with implications in terms of earthquake source mechanisms and, ultimately, on seismic hazard assessment. At the level of individual structures, significant uncertainties remain regarding the way active faults dominantly release tectonic strain: by a single mode in the magnitude distribution or by a continuous Gutenberg-Richter distribution applied to individual fault [8-10].

In this work, we use geodetic and seismological observations to document the coseismic and aseismic deformation associated with the 18 January 2017 multiple moderate seismic events (main event $M_{W}$ 5.5) that struck the Campotosto area in central Italy. This swarm of moderate-size events is part of the 2016-2017 central Italy seismic sequence that affected the central Apennines starting on 24 August 2016 with a $\mathrm{M}_{\mathrm{W}} 6.0$ event in the Amatrice area (Figure 1), and then culminated with the 30 October $2016 \mathrm{M}_{\mathrm{W}} 6.5$ largest event [11]. The geodetic, seismological, and geological studies published so far (e.g., [11-20]) agree in attributing the bulk of the 2016-2017 central Italy seismic sequence to the progressive rupture of different segments of two main NW-SE striking extensional structures of the central Apennines, the Laga Mts., and Mt. Vettore-Mt. Bove normal fault systems (Figure 1). Both the fault systems have been considered to be the surface manifestation of moderate- to large-magnitude earthquakes (e.g., [21,22]). The Laga Mts. fault system (alternately known as the Mt. Gorzano fault) extends for about $28 \mathrm{~km}$ dipping WSW and is well known in the literature (e.g., [21-28]). The fault plane is well exposed in the central-southern portion of the structure where the fault scarps are evident at the base of the western flank of the Laga Mts. (Campotosto segment), progressively losing a clear surface expression towards the northern termination (in the Amatrice basin) [25,27]. While some authors define the Laga Mts. fault structure as a single continuous segment (e.g., [24,25]), other studies propose instead a segmentation of the fault system into two independent seismogenic sources-the minor ( $10 \mathrm{~km}$ long) Amatrice fault northern segment, bounding the Amatrice basin, and the $\sim 20 \mathrm{~km}$ long Campotosto fault southern segment (e.g., $[21,26,27])$, bounding the Campotosto basin. 


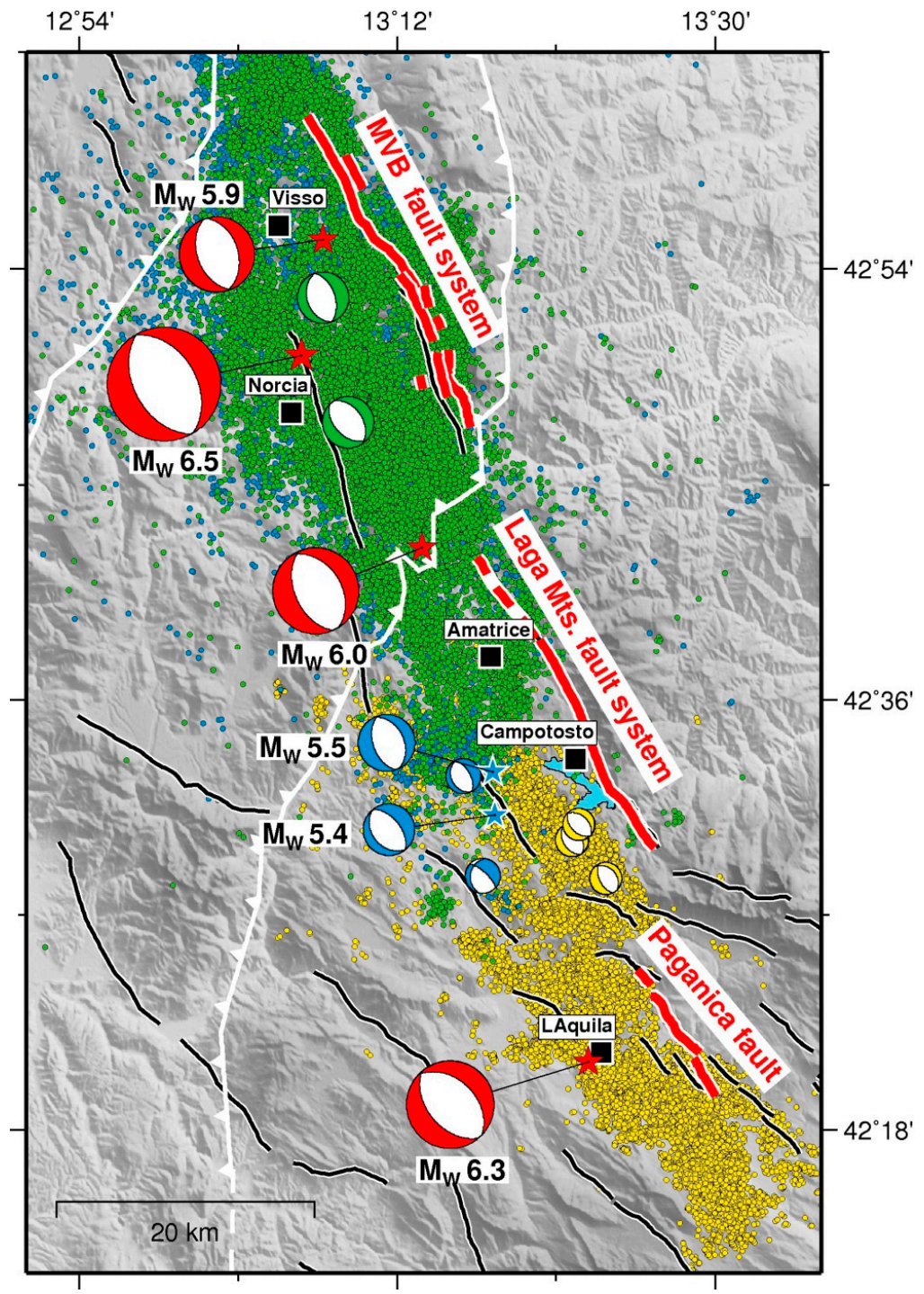

Figure 1. Seismotectonic map of the study area. Solid black lines are the major active faults of the area [28], while the red lines represent the Mt. Vettore-Mt. Bove (MVB) and the Laga Mts. fault systems, and the Paganica fault [26]. The white barbed lines show the preexisting compressional fronts [29,30]. Yellow dots are relocated aftershocks of the 2009 L'Aquila sequence [31], green circles are relocated aftershocks of the 2016-2017 central Italy seismic sequence between 24 August and 30 November 2016 [11]; blue circles are events between 1 December 2016 and 17 January 2017 [32]; the red stars indicate the epicenters of the three largest shocks $\left(\mathrm{M}_{\mathrm{W}}\right.$ 6.0, 5.9 and 6.5$)$ of the 2016-2017 central Italy and of the main shock $\left(\mathrm{M}_{\mathrm{W}}\right.$ 6.3) of the 2009 L'Aquila sequences, respectively; the blue stars show the location of the four largest shocks $\left(\mathrm{M}_{\mathrm{W}} \geq 5\right)$ of the 18 January 2017 Campotosto earthquake sequence. The beach-balls display focal solutions from the INGV Time Domain Moment Tensor Catalogue (http://cnt.tm.ingv.it/tdmt). Red, main shocks of the 2009 and 2016-2017 seismic sequences; yellow, $M$ > 5 earthquakes of the 2009 sequence; green, $M_{W}>5$ events of the 2016-2017 seismic sequence; blue, largest events of the 18 January 2017 Campotosto seismic swarm.

In recent times, the Laga Mts. fault system was active in the Amatrice area with the rupture of the 24 August $2016 \mathrm{M}_{\mathrm{W}}$ 6.0 Amatrice earthquake. In historical times, it is presumed also to have been struck by another similar large earthquake (a M 6.3 event in October 1639 [33]). On the contrary, the historical catalogue lacks evidence of $M>6$ seismic events [33] in the southern-central Campotosto segment, which in recent decades has only been affected by small to moderate seismic sequences in the 1990s [24], in April 2009 [34-36], and in January 2017 [11,27,37]. The Campotosto fault shows, however, 
evidence of Late Pleistocene-Holocene movements, as shown by surface-rupturing events observed in trenches dug across the fault scarps [21,22]. Based on these observations the Campotosto fault was considered active and as a potential seismic gap [21,22], with an associated potential maximum magnitude of the order of M 6.5 [21,22,27].

Regarding the 18 January 2017 seismic sequence, the first shock hit at 9:25 UTC with a $\mathrm{M}_{\mathrm{W}} 5.1$ event at depth of about $9 \mathrm{~km}$ [11]. Around one hour after the first earthquake, a second and a third shock followed with magnitudes of $\mathrm{M}_{\mathrm{W}} 5.5$ and 5.4, respectively, in the same area [11]. Finally, a fourth event of magnitude $M_{W} 5.0$ struck the same region in the early afternoon (Figure 1). All four main shocks likely nucleated on the deepest portion of the northwestern half of the Campotosto fault, at a depth of 9-11 km [11], with normal fault mechanisms (http:/cnt.rm.ingv.it/tdmt) in agreement with the NE-SW direction of active extension across this sector of the central Apennines [38]. As mentioned above, the Campotosto fault segment was also partially activated during the April 2009 L'Aquila seismic sequence [31,34-36], when several small- to moderate-size events struck the southeastern deep portion of the Campotosto fault (Figure 1), with a major event of magnitude $\mathrm{M}_{\mathrm{W}} 5.4$ on 9 April $2009[31,34]$. In general, all the small to moderate seismic sequences affecting the hanging wall of the Campotosto fault, mainly nucleated along the deeper portions of the seismogenic fault, along the down-dip prolongation of the major mapped geological SW-dipping Laga Mts. normal fault system outcropping on the western flank of the Mt. Gorzano. Although some authors [21-28] interpreted the Campotosto seismogenic fault in continuity with the geological fault trace, others [39,40] have instead suggested the lack of vertical continuity between the deep fault and the surface trace of the Campotosto fault.

In the following, we analyze InSAR deformation maps and GPS observations in combination with seismological data, to constrain the parameters of the activated fault/faults and the slip distribution associated with the two largest events of the 2017 seismic sequence and to evaluate how these earthquakes affected the static stress acting on the unruptured portions of the Campotosto fault. With respect to previous studies [27,37], the InSAR observations, the GPS and high-rate GPS (HR-GPS) measurements, and the strong-motion data used in this work, represent the most comprehensive data set for the 18 January 2017 Campotosto multiple events, allowing us to retrieve a robust estimate of both the geometry and the kinematic model of the causative fault. Our findings offer therefore important insights on the debated geometry of the active Campotosto fault and on the unruptured portions of the causative fault, in the context of its proximity to a major dam along the Campotosto lake.

\section{Data}

\subsection{InSAR Data}

The two satellites of S1 constellation (Sentinel-1A and Sentinel-1B) allowed us to collect numerous images over central Italy. We used a total of 24 images in the so-called TOPSAR (Terrain Observation with Progressive scan Synthetic Aperture Radar) mode (https:/earth.esa.int/web/sentinel/technical-guides/ sentinel-1-sar/products-algorithms/level-1-algorithms/topsar-processing) that were acquired between 13 December 2016 and 30 April 2017, every 6 days on the ascending orbit. Many interferograms was calculated with the purpose of identifying the most coherent SAR deformation maps. We used standard Differential SAR interferometry [41]. The topographic phase component was removed exploiting the DEM (Digital Terrain Model) provided by Shuttle Radar Topography Mission - SRTM [42] with a resolution of $30 \mathrm{~m}$ per pixel. The resulting interferograms were filtered by applying the Goldstein filter [43] to reduce interferometric phase noise. Among the 107 interferograms, we selected the more coherent ones, aiming at keeping as much as possible detailed fringe patter, and consequently get a more spatially detailed field of ground deformation. Indeed, the two best interferograms show a clear fringe pattern of the coseismic displacements (Figure 2). 


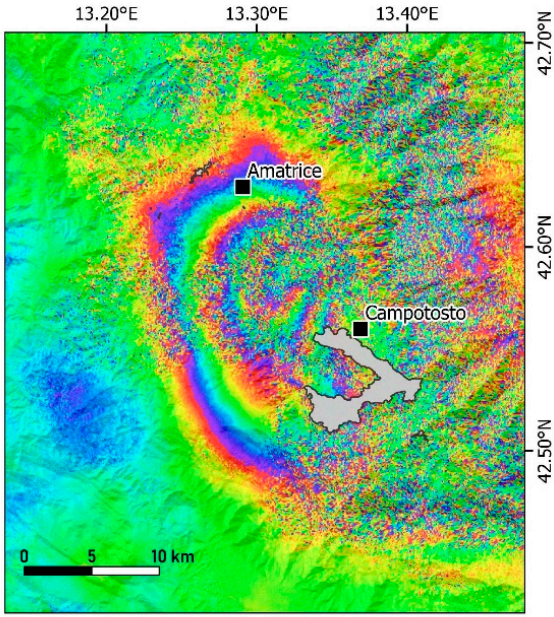

a)

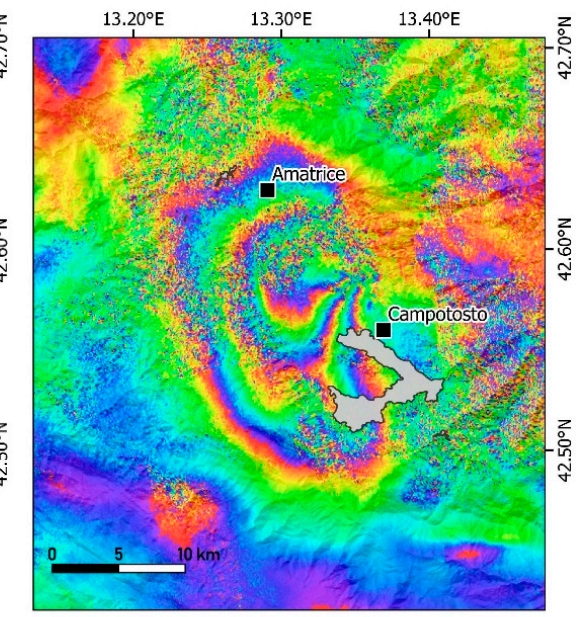

b)

Figure 2. The two best S1 wrapped interferograms (ascending orbits). (a) the 13 December 2016/11 February 2017 pair; (b) the 13 December 2016/25 March 2017 pair. Each fringe represents about $2.8 \mathrm{~cm}$ of Line-Of-Sight deformation.

These interferograms are related to the image pairs 13 December 2016/11 February 2017 and 13 December 2016/25 March 2017, and are consistent with each other (i.e., they show the same pattern of three distinct fringes that seem to close NE against the western slope of the Mt. Gorzano). As already discussed in [27], the descending orbit images did not produce noise free (good coherence) interferograms. In the modeling, we use the interferogram that contains the shortest time period after the 18 January seismic events, i.e., we exploited the interferogram obtained from the 13 December 2016 and 11 February 2017 acquisitions. The interferogram was then unwrapped [44] and finally geocoded to obtain the ground deformation map.

Due to the time elapsed between the main shocks and the post-earthquakes image (about 1 month), the interferogram contains the cumulated coseismic effect of the four $M>5.0$ earthquakes and the post-seismic deformation eventually occurred after the 18 January 2017. In the displacement pattern, we observe a major lobe of increasing LOS (Line-Of-Sight) displacements (with maximum value of about $8 \mathrm{~cm}$ ) away from the satellite between Amatrice and Campotosto, in the hanging wall of the main shocks (Figure 3a). 

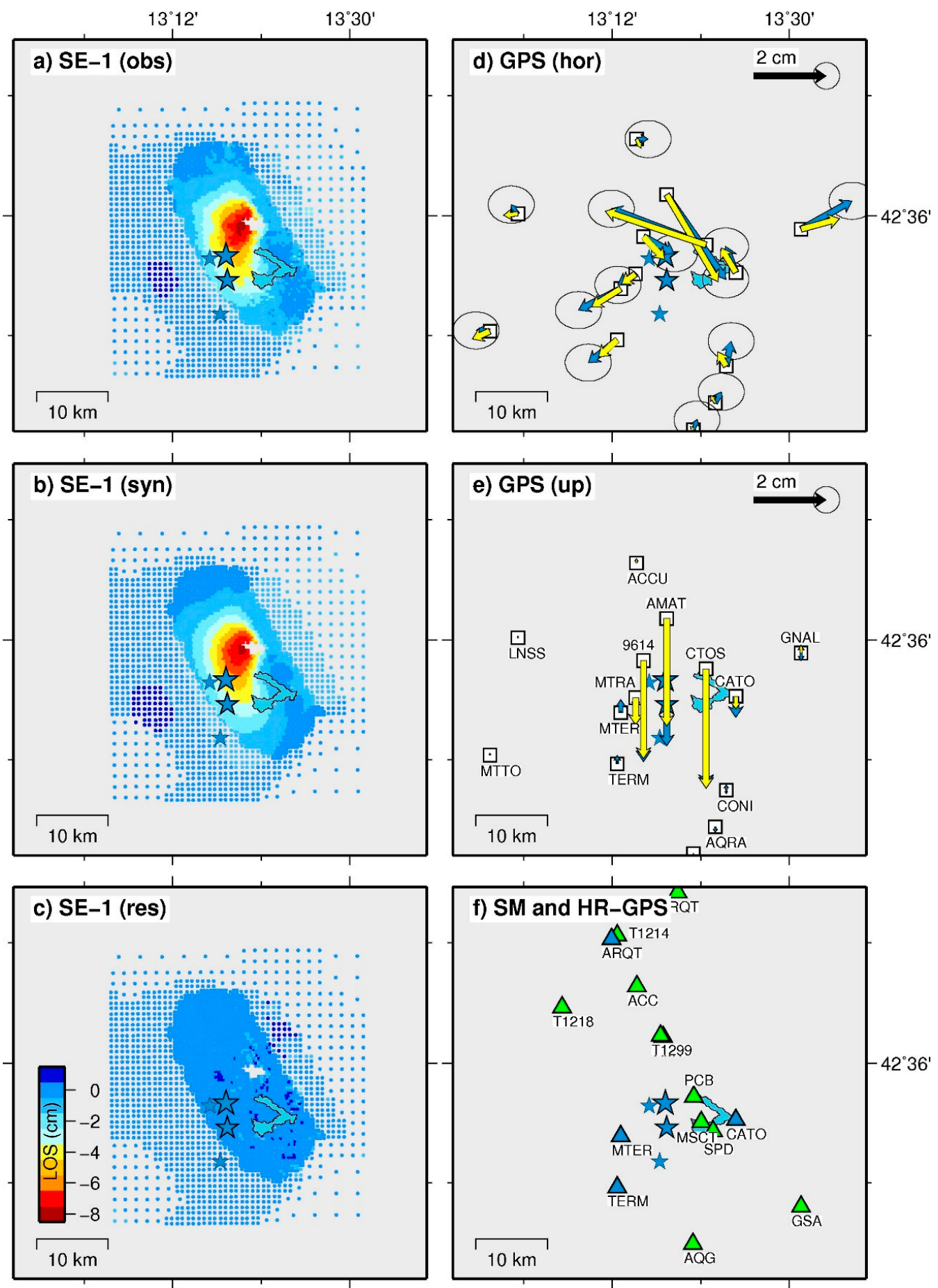

Figure 3. Cumulative displacements of the 18 January 2017 Campotosto multiple events seismic sequence. (a) Observed, (b) modeled and (c) residual SE-1 interferograms (relative to the 13 December 2016/11 February 2017 pair). Observed (blue; error ellipses at 95\% confidence interval) and modeled (yellow) cumulative GPS displacements calculated relative to the same time span of InSAR acquisitions: (d) horizontal, and (e) vertical displacements, respectively. (f) Distribution of the strong-motion stations (SM, green triangles) and high-rate GPS receivers (HR-GPS, blue triangles) used to estimate the kinematic model of the two largest events of the 18 January seismic sequence. The blue stars are the four largest $\left(\mathrm{M}_{\mathrm{W}} \geq 5\right)$ events of the 2017 seismic sequence. 


\subsection{GPS Static Offsets Data}

We have analyzed GPS data from Global Navigation Satellite System-GNSS stations managed by the Italian Civil Protection Department (DPC), INGV, and ISPRA (Istituto Superiore per la Protezione e la Ricerca Ambientale), integrated with episodic GPS data collected in the epicentral belonging to the IGM95 network [45]. GPS data spans from 11 December 2016 to 11 February 2017, covering the 18 January 2017 multiple events seismic sequence. In total, we used data from 27 GPS sites, with $59 \%$ of the sites (16 sites) located within $30 \mathrm{~km}$ from the main epicenters (Figure 3d,e). We used the software Bernese version 5.2 [46], provided by the Astronomical Institute of the University of Bern (AIUB), to obtain GPS sites cumulated (coseismic and initial post-seismic) offsets.

We have simultaneously analyzed GPS data (network solution) using precise orbits obtained from CODE (Center for Orbit Determination in Europe) analysis center. For each station, receiver-antenna couple has been corrected by using the IGS08 absolute antenna phase center correction file "PCV.I08" provided by AIUB. Earth rotation parameters (ERPs), receiver and satellite clock drifts and tropospheric zenith delays, from CODE analysis center, coordinates, and velocities of International GNSS Service-IGS stations were downloaded from igs.ensg.ign.fr. We applied corrections to the observations for effects of ocean loading by using the Finite Elements Solution 2004 (FES2004) tidal model provided by the Ocean Tide Loading web service (http://holt.oso.chalmers.se/loading) as well as effects of atmospheric tidal loading. To resolve ambiguities, we processed the baselines separately using the Quasi-Ionosphere-Free (QIF) strategy. Troposphere parameters estimation has been performed using the Global Mapping Function (GMF wet and dry) model [47], where Zenith Path Delay (ZPD) corrections are computed based on Global Pressure Temperature model at 2-hour intervals, while the horizontal gradient parameter is estimated daily at each site.

Local geodetic datum is set to IGS14 using IGS core sites. We estimated daily GPS site coordinates in loosely constrained mode aligning the solutions onto the IGS14 reference frame using a 6-parameter Helmert transformation (translation and rotation) and 6 IGS sites. We aligned all pre- and post-seismic solutions to 12 December 2016 and 11 February 2017 IGS14 positions, respectively, for the 27 sites. We then compared the coordinate and variance files of the two solutions using an Helmert transformation allowing only translation in $\mathrm{x}, \mathrm{y}$ and $\mathrm{z}$ (no rotation and no scale factor variation allowed), using only IGS sites. As far as only one survey-style site we compared pre- and post-seismic solutions referring to the 2 March 2017, because of the availability of data collected. We obtained for each site a solution in terms of latitude, longitude, and elevation offsets, with a mean root-mean-square (RMS) between 1.3 and $1.1 \mathrm{~mm}$ in longitude and latitude, respectively, and around $3 \mathrm{~mm}$ in elevation.

The maximum static displacements are $\sim 3-3.5 \mathrm{~cm}$ of subsidence near Amatrice (AMAT) and Campotosto (CTOS) (Figure $3 \mathrm{e}$ ) and $\sim 2.8 \mathrm{~cm}$ of horizontal movement towards southeast at AMAT site and towards northwest at CTOS site (Figure 3d). Differently from previous studies that have taken into consideration only horizontal GPS offsets [27] or a very limited number of GPS data [37], our joint inversion uses a more comprehensive data set and the full 3-D static displacement field. In addition, we take advantage of the new near-field GPS measurements at stations CTOS, 9614, and CATO (near Campotosto lake) that were not previously used. The GPS deformation pattern highlights a general NE-SW oriented extension in agreement with the deformation field depicted by the InSAR measurements.

\subsection{Strong-Motion and High-Rate GPS Data}

The two largest shocks of magnitude $\mathrm{M}_{\mathrm{W}} 5.5$ and 5.4, were well recorded by 11 and 14 strong-motion stations in the near-source, respectively, belonging to the RAN (Rete Accelerometrica Nazionale, http://ran.protezionecivile.it/IT/index.php) and to the INGV [48,49] accelerometric networks (Figure 3f). The accelerograms were processed to remove the instrument response, band-pass filtered between $0.02-0.5 \mathrm{~Hz}$, and time integrated to obtain ground velocity histories. The processed time histories were then resampled at 10 samples per second. 
The strong-motion dataset has been integrated with the HR-GPS displacement time series obtained from the closest stations for the largest event. The HR-GPS waveforms were then converted to velocity time series by taking the time derivatives and then filtered in the same frequency band of the seismic data. In addition to the standard GPS processing approach used to obtain daily solutions, for each large event, we performed the analysis of HR-GPS data from 12 sites, two of which were in the epicentral area. The high-rate analysis strategy was performed by using the GIPSY-OASIS II software released by Jet Propulsion Laboratory (JPL, http://gipsy-oasis.jpl.nasa.gov), in a kinematic mode [50], to obtain a solution for every epoch of measurement. The available HR-GPS data sampling was at $1 \mathrm{~Hz}$ and $10 \mathrm{~Hz}$. The details of the performed analysis can be found in previous studies [51]. In addition to the processing of the data, a further analysis has been applied to the resulting high-rate displacement time series to minimize residual noise due to temporal or spatial correlations that could affect the determination of the static coseismic offsets. Firstly, we used the obtained time series of the day before the $\mathrm{M}_{\mathrm{W}} 5.5$ and the $\mathrm{M}_{\mathrm{W}} 5.4$ main events to apply a sidereal filtering [52] to minimize the multipath contribution in the GPS waveforms. Secondly, as previously done for long-term time series [53], for each component, the high-rate GPS waveforms for stations located in undeformed region were stacked to obtain a common-mode signal, probably due to mismodeled regional troposphere artifacts, to be subtracted from the GPS waveforms for the sites in the epicentral area.

\section{Inversion Results}

We first invert the static deformation as depicted by GPS static displacements to determine the fault geometry assuming a uniform slip patch. Then, the best-fit uniform slip fault parameters are used as a priori information for estimating the cumulative geodetic slip distribution using both InSAR and GPS datasets. Finally, adopting the same fault geometry, we retrieve the rupture process of the two largest events of the 18 January 2017 sequence by jointly inverting the strong-motion waveforms, the HR-GPS waveforms, and the HR-GPS-derived coseismic static offsets.

\subsection{Static Finite-Fault Modeling of the Cumulative Sequence}

We performed the source modeling of static deformation using rectangular dislocations in an elastic, homogenous and isotropic half-space [54]. In particular, we carried out a non-linear optimization of the fault geometry with uniform slip, followed by a linear inversion for the distribution of slip on the best-fit uniform slip fault plane, subdivided into small fault patches (e.g., [55,56]). We used a simulated annealing algorithm [57] to determine the best-fit model, describing the geometry and the slip of the causative fault plane that produces the least-squares best-fit. Then, we used a Monte Carlo simulation technique [58] to estimate the confidence intervals of the estimated model parameters (Figure S1). Because surface displacements located above the shallower part of the causative fault are most sensitive to the details of the slip distribution and may not be compatible with the uniform slip assumed for the evaluation of the best-fitting fault geometry, we use only GPS data for the estimation of the best-fitting uniform slip, excluding the InSAR displacements in the non-linear inversion. The best-fit uniform slip model is described by a $\sim 150^{\circ} \mathrm{NW}$-SE-trending and $\sim 50^{\circ} \mathrm{SW}$-dipping fault plane passing through the hypocentral locations (Figure 4, violet box). The average uniform slip is $0.44 \mathrm{~m}$ which, using a value of 30 GPA for rigidity, yields an estimated cumulative seismic moment of $6.06 \times$ $10^{17} \mathrm{Nm}$, equivalent to a $\mathrm{M}_{\mathrm{W}} 5.82$ earthquake. Horizontal and vertical GPS displacements are well reproduced (RMS values of $7.16 \mathrm{~mm}$ ) with the exception of the vertical component of the near-field sites AMAT, CATO and CTOS, and of the horizontal components of AMAT and CATO sites, which cannot be well reproduced with a uniform slip model (Figure S2). On the other hand, these GPS sites provide strong constraints on the edges of the uniform slip fault model. 


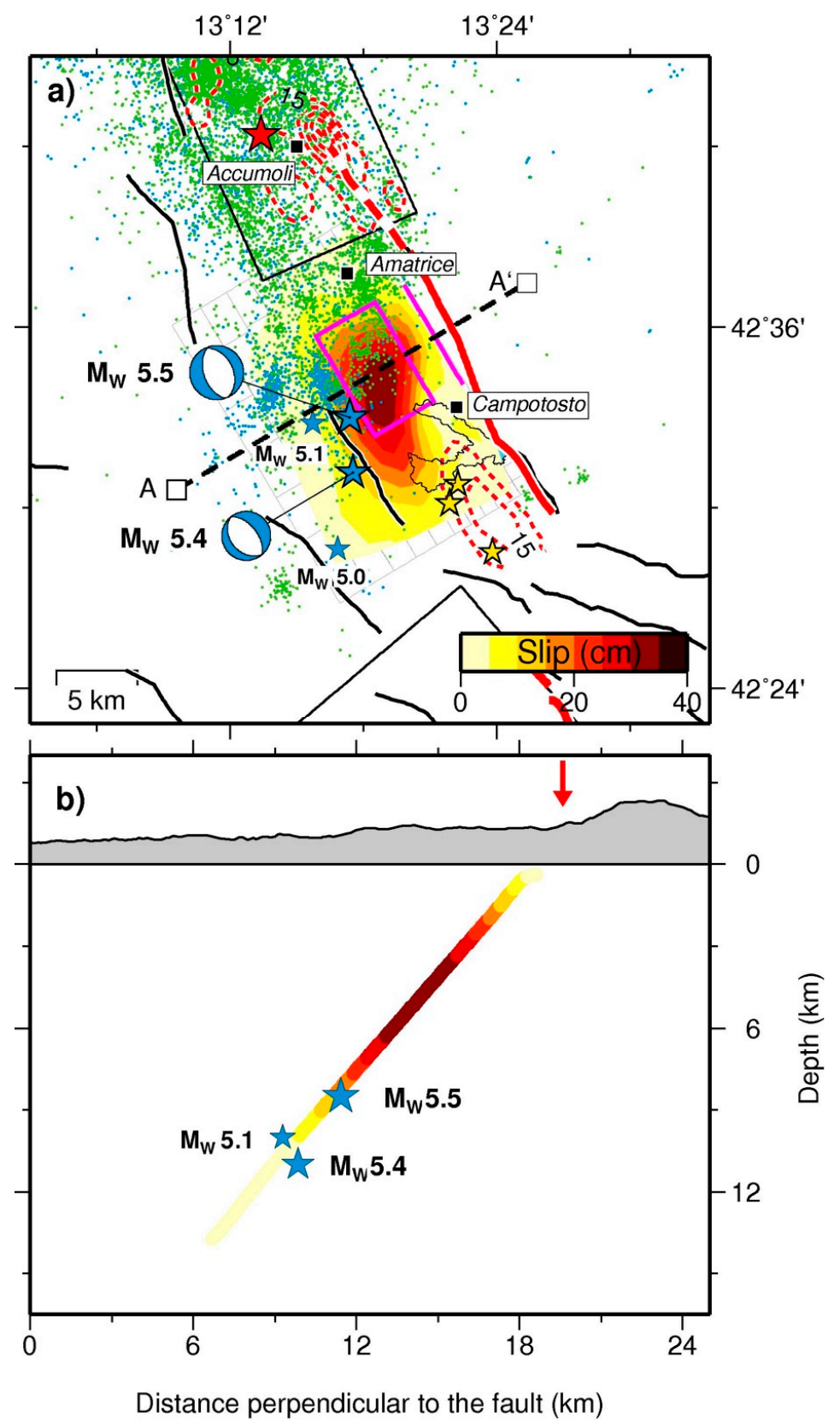

Figure 4. Static joint cumulative coseismic slip model of the 18 January 2017 Campotosto earthquake sequence obtained by inverting InSAR and GPS data. The contouring (in $\mathrm{cm}$ ) indicates the modeled slip distribution of the 2009 Campotosto sequence [36] and the coseismic slip of the 24 August 2016 $\mathrm{M}_{\mathrm{W}} 6.0$ Amatrice earthquake [12]. (a) Green circles are relocated aftershocks of the 2016-2017 central Italy seismic sequence between 24 August and 30 November 2016 [11]; blue circle are events between 1 December 2016 and 17 January 2017 [32]. The yellow stars represent the largest shocks $(M>5)$ of the 2009 sequence. The violet box represents our best-fit uniform slip solution. Other symbols as in (b) Cross section drawn perpendicular to the strike of the fault, showing the amount of slip at depth and the 2017 major events (blue stars) location. The red arrow indicates the geological fault trace of the Campotosto fault.

In a second step, we estimate variable slip on the fault plane by subdividing the fault into smaller patches with increasing size in depth to maintain a good model resolution at the deeper portions of the fault (e.g., [59]). The shallower patches are $1.0 \mathrm{~km} \times 1.0 \mathrm{~km}$, while the deeper ones are $3.11 \times$ $3.11 \mathrm{~km}$. We apply positivity constraints and regularize the linear inversion by applying smoothing via 
a finite-difference approximation of the Laplacian operator (Figure S3). Before modeling, the InSAR interferograms were down-sampled using a resolution-based resampling algorithm [60]. Additional terms, consisting of a linear ramp for the InSAR displacements, were also included in the static inversions, to minimize the effect of any residual long-wavelength orbital errors in InSAR maps on the solution. In addition, we assigned relative weighting factors to InSAR and GPS displacements. By examining the misfit reduction for the different datasets as a function of the relative weight (Figure S4), we assigned a weighting ratio of 2 to the GPS offsets (i.e., GPS was up-weight by a factor of 50). The results of the variable slip inversion show a significant improvement in RMS reduction of GPS data (7.16 versus $2.58 \mathrm{~mm}$ ), mostly accomplished by reduction in the vertical misfit. The relatively simple pattern of the cumulative coseismic InSAR interferogram is also well reproduced by our model, with very small residual (RMS $2.50 \mathrm{~mm}$ ). The variable slip model is showed in Figure 4a. It is characterized by a major asperity with $\sim 0.4 \mathrm{~m}$ of maximum slip, almost contained within the uniform slip fault (violet box in Figure 4a), at a depth between 1-2 km and $9 \mathrm{~km}$, up-dip respect to the hypocenters of the largest events of the sequence (Figure $4 \mathrm{~b}$ ). In addition, some of the estimated cumulative slip extends towards the $\mathrm{SE}$ in the area of the second $\left(\mathrm{M}_{\mathrm{W}}\right.$ 5.4) main event of the sequence. The result of the cumulative geodetic inversion, using a value of $30 \mathrm{GPa}$ for rigidity, gives an estimated cumulative seismic moment of $9.29 \times 10^{17} \mathrm{Nm}$ equivalent to a $\mathrm{M}_{\mathrm{W}} 5.95$ earthquake.

\subsection{Testing the Vertical Continuity of the Campotosto Fault}

In this section, we investigate the vertical extent of the Campotosto fault exploring alternative geometries for the segment activated during the 18 January 2017 multiple events seismic sequence. Previous studies, discussed in the Introduction, suggest that the up-dip extension of the recent seismic sequences affecting the Laga basin match the superficial expression of the exposed fault plane which bounds the western slope of Mt. Gorzano. On the other hand, the lack of events located at shallow depths (between 0 and $5 \mathrm{~km}$ ) of the 2009 aftershock catalogue [31,34], spurred a debate on the connection between the seismogenic deep source of 2017 and 2009 aftershock sequences with the trace of fault plane at the surface $[25,27,34,36,39,40]$. In particular, the geological interpretation of seismic profiles of [39] suggested that the deep seismogenic fault responsible for the 2009 sequence would not correspond with the exposed fault plane, with the latter confined above the interpreted Gorzano-Acquasanta thrust sheet at a depth of about $4 \mathrm{~km}$, where according to the authors, the exposed normal fault would flatten westward. A more recent tomographic model [40] also suggests a similar interpretation, according to which the recent $2017 \mathrm{M}>5$ events would have developed along the same interpreted thrust ramp that would have activated in 2009, buried below the Laga basin. According to [40] the upper termination of this deep ramp, that would therefore confine the seismicity at depth greater than $5-6 \mathrm{~km}$, is traced around $4-5 \mathrm{~km}$ depth (see Figure 6 of [40]). Finally, the relocated seismicity distribution of the April 2009 seismic sequence that affected the southern half of the Campotosto fault segment, appears to flatten at depth [31,34]. In contrast with a variable dip, previous studies of the 2009 sequence [36] did not required to increase the complexity of the Campotosto fault geometry from a simple planar geometry.

To test the effect of a possible lack of vertical continuity of the deep seismogenic fault, we performed an inversion of our geodetic dataset confining slip below this depth interval (Figure 5). This test indicates that (1) excluding the shallower patches in the inversion increases slip in the deeper portions of the fault (max slip about $80 \mathrm{~cm}$, Figure 5b), and (2) that it is not possible to reproduce the observed displacements by slip on a deep source alone (Figure $5 c, d$ ). In fact, the maximum InSAR and GPS deformation observed between Amatrice and Campotosto are not completely reproduced, resulting in large residuals in the source region that makes the RMS of the data significantly worse (6.43 versus $2.58 \mathrm{~mm}$ and 9.15 versus $2.50 \mathrm{~mm}$ for GPS and InSAR measurements, respectively) than our preferred model in which the retrieved slip is continuous all along the fault plane, from hypocentral depths to $1-2 \mathrm{~km}$ depths (Figure $4 \mathrm{~b}$ ). 

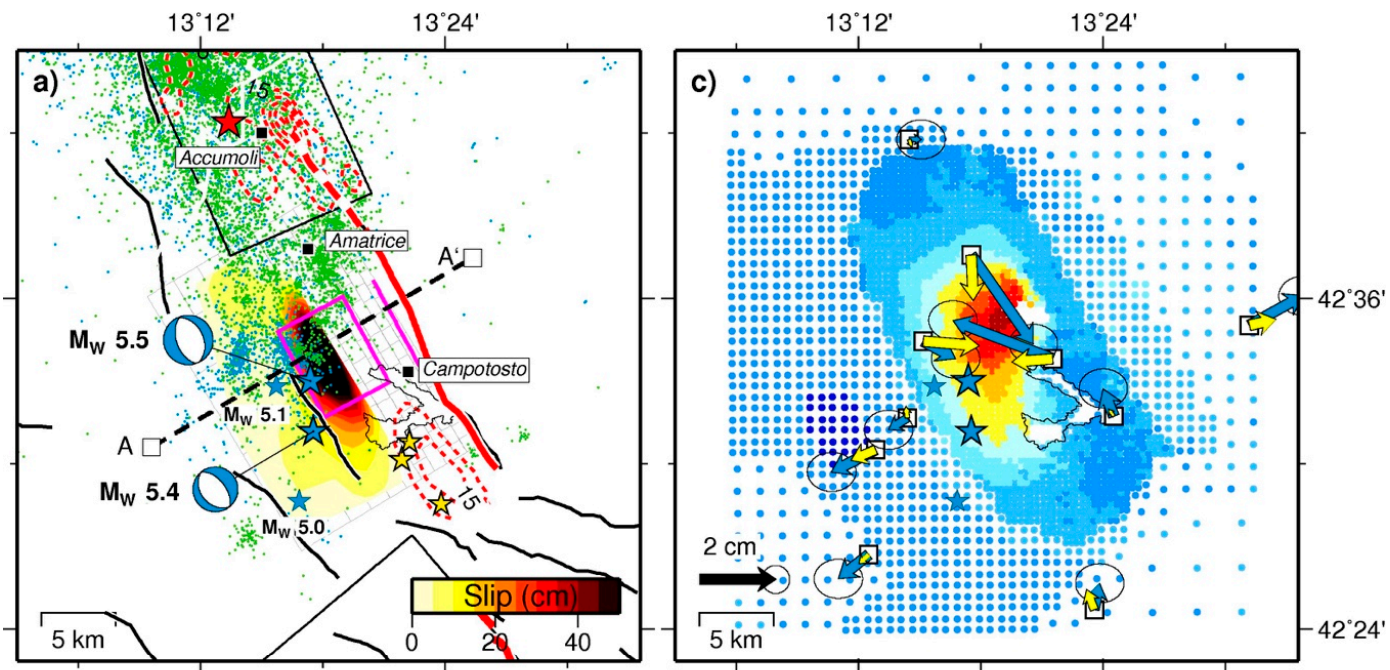

Distance perpendicular to the fault $(\mathrm{km})$
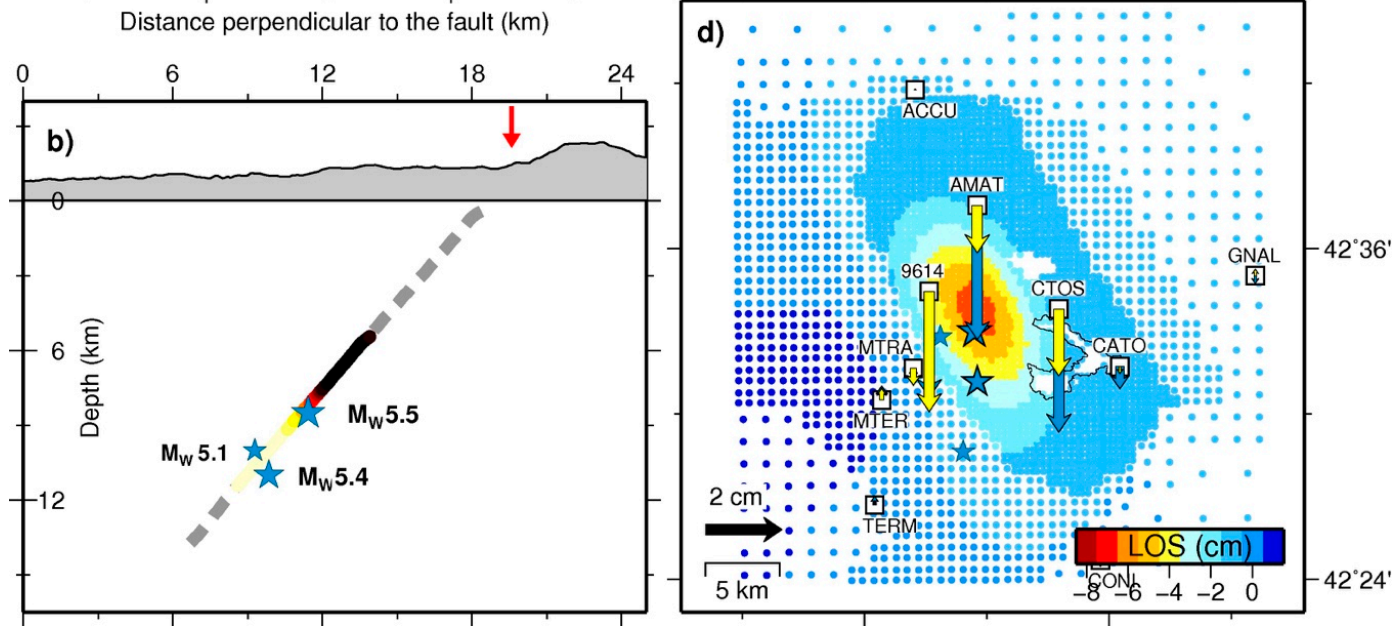

Figure 5. Testing the vertical continuity of the Campotosto fault imposing the top of the fault at $5 \mathrm{~km}$ depth. (a) Map view; (b) cross section; (c,d) fit to the InSAR (observed in panel c, synthetic in panel d) and GPS data (horizontal components in panel c, vertical component in panel d). Symbols as in Figures 3 and 4.

Due to the possible uncertainties about the depth at which the Campotosto fault plane has been hypothesized to flatten $[39,40]$, we inverted InSAR and GPS data fixing the up-dip termination of the deep fault at various shallower depths $(<5 \mathrm{~km})$. The results of these inversions clearly show that fixing the top of the fault plane at $2 \mathrm{~km}$ depth (Figure 6 and Figures S5-S7), increases the misfit to the geodetic data mostly associated with the small deformation along the surface trace of the fault. Increasing the depth of the top of the fault, further degrades the fit to the data (Figure S7). It is, therefore, clear that deep sources of fault slips unconnected with the surface trace of the fault cannot reproduce the geodetic data, challenging the hypothesis of reactivation of the upper Campotosto fault induced by a deeper seismogenic fault $[39,40]$. 
$13^{\circ} 12^{\prime}$
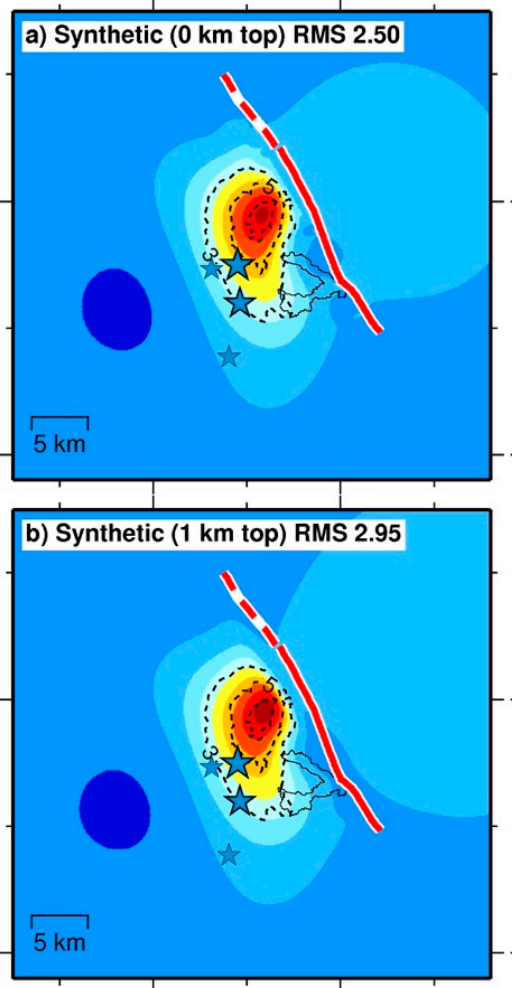

c) Synthetic (2 km top) RMS 4.17

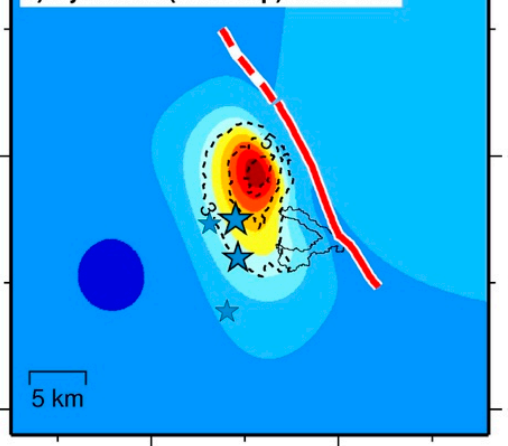

d) Synthetic (3 km top) RMS 5.54

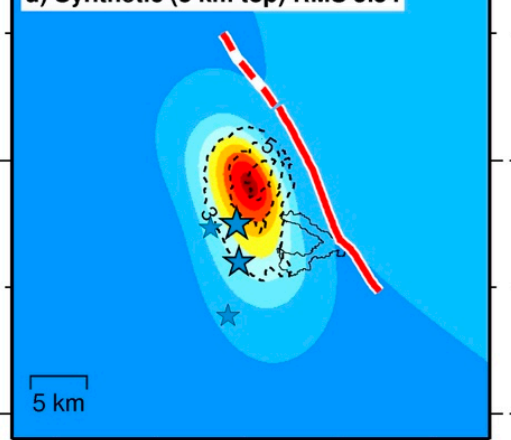

$13^{\circ} 12$

$13^{\circ} 24$
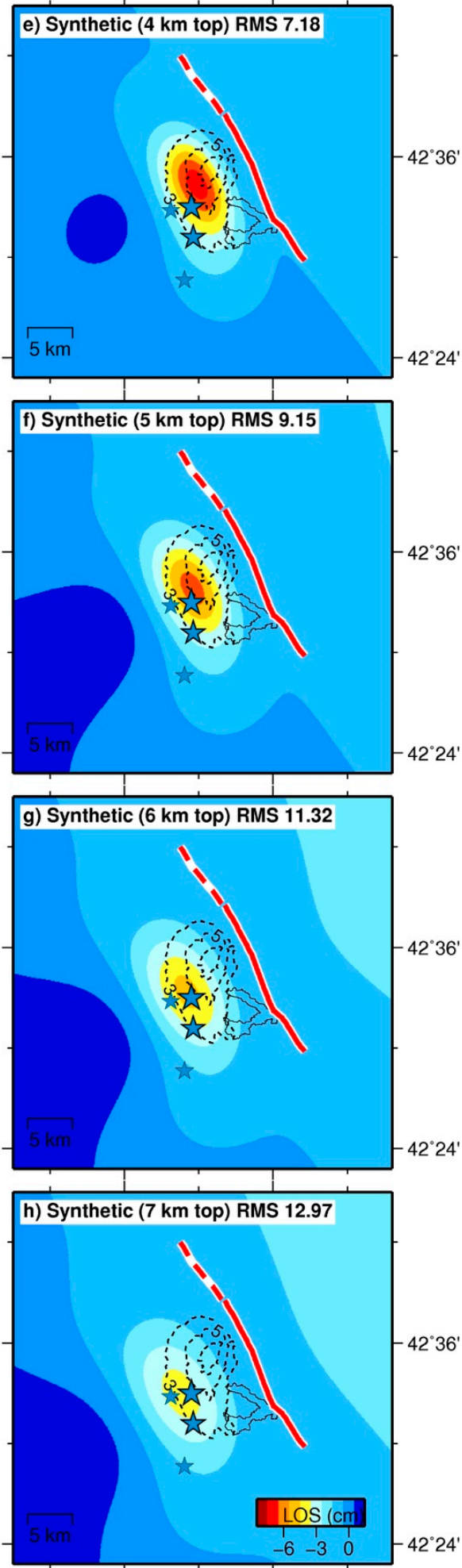

Figure 6. Testing the vertical continuity of the Campotosto fault. Panels (a-h) show the synthetic interferograms computed by fixing the top of the modeled fault plane at increasing depth from 0 to $7 \mathrm{~km}$ (step $1 \mathrm{~km}$ ). The dashed lines (in $\mathrm{cm}$ ) represent the observed LOS deformation field. Please note that increasing the depth of the fault significantly worsens the fit to the data. 


\subsection{Kinematic Finite-Fault Slip Inversions of the Two Largest Events}

We have inverted strong-motion waveforms and HR-GPS data (both waveforms and static offsets) to retrieve separately the rupture process of the two largest events on Campotosto fault on 18 January 2017. The static offset from HR-GPS waveforms is retrieved comparing the 3-D average position (and the relative standard deviation) in a $10 \mathrm{~s}$ time windows and after the earthquake. The inversion code consists of a non-negative, least-squares inversion method with simultaneous smoothing and damping (e.g., $[12,61])$. Our approach assumes the propagation to occur with constant rupture velocity, allowing the use of multiple time windows to account for variation in rupture propagation and local rise time [12]. The rupture velocity and rise time are selected iteratively by performing inversions with different parameter values, while measuring the fit to the data. The fit is computed through the variance reduction parameter defined in [61]. The green functions were calculated using a frequency wave number integration program by using the Central Italian Apennines (CIA) velocity model [62] and filtered between 0.02 and $0.5 \mathrm{~Hz}$ as the recorded data.

The previous analysis of geodetic data allowed us for a better identification of the best causative fault to adopt in the inversion. The fault model is a plane striking $152^{\circ}$ and dipping $48^{\circ}$ to the SW and with fault dimension of $10 \mathrm{~km} \times 14 \mathrm{~km}$. During the inversion we allowed rise time and rupture speed to vary between $0.3-1.5 \mathrm{~s}$ (step $0.1 \mathrm{~s}$ ), and $2.0-3.5 \mathrm{~km} / \mathrm{s}$ (step $0.1 \mathrm{~km} / \mathrm{s}$ ), respectively. The fault plane was discretized into fault patches each with $2 \mathrm{~km} \times 2 \mathrm{~km}$ dimension, and the rake was allowed to vary between $-70^{\circ}$ and $-100^{\circ}$. Because of the moderate magnitude of the two events, the kinematic fault models have been obtained by imposing a single-window fault rupture.

\subsubsection{The $\mathrm{M}_{W} 5.5$ Earthquake}

Time histories from 11 seismic stations and 4 HR-GPS sites as well as the static offsets retrieved from the AMAT HR-GPS waveform were jointly inverted to infer the best-fit rupture model shown in Figure 7. In this model, the fault was parameterized using 35 patches. The fault top reaches $0 \mathrm{~km}$ depth and the hypocentral depth is $8.5 \mathrm{~km}$. This model is characterized by a constant rise time of $1.1 \mathrm{~s}$, and a best-fit rupture velocity of $3.2 \mathrm{~km} / \mathrm{s}$. The inferred seismic moment is $2.81 \times 10^{17} \mathrm{Nm}$ corresponding to a $\mathrm{M}_{\mathrm{W}} 5.59$ earthquake. An interesting feature of this model is a relatively fast rupture velocity $(3.2 \mathrm{~km} / \mathrm{s})$ and a marked up-dip directivity. The main patch of slip (about $8 \mathrm{~km}$ up-dip from the hypocenter) has a maximum slip of about $50 \mathrm{~cm}$ and a rake close to $\sim 90^{\circ}$. Noteworthy, the kinematic finite-fault best-fit model requires significant slip up to very shallower depths (1-2 km depth). This result highlights that the earthquake ruptured the upper part of the fault (depth $<5 \mathrm{~km}$ ), consistently with the vertical continuity of the fault between the surface trace and its deepest part (depth $>8 \mathrm{~km}$ ). The total variance reduction is about $69 \%$ and both the synthetic seismograms and HR-GPS time series match well the observations (Figure 7). 


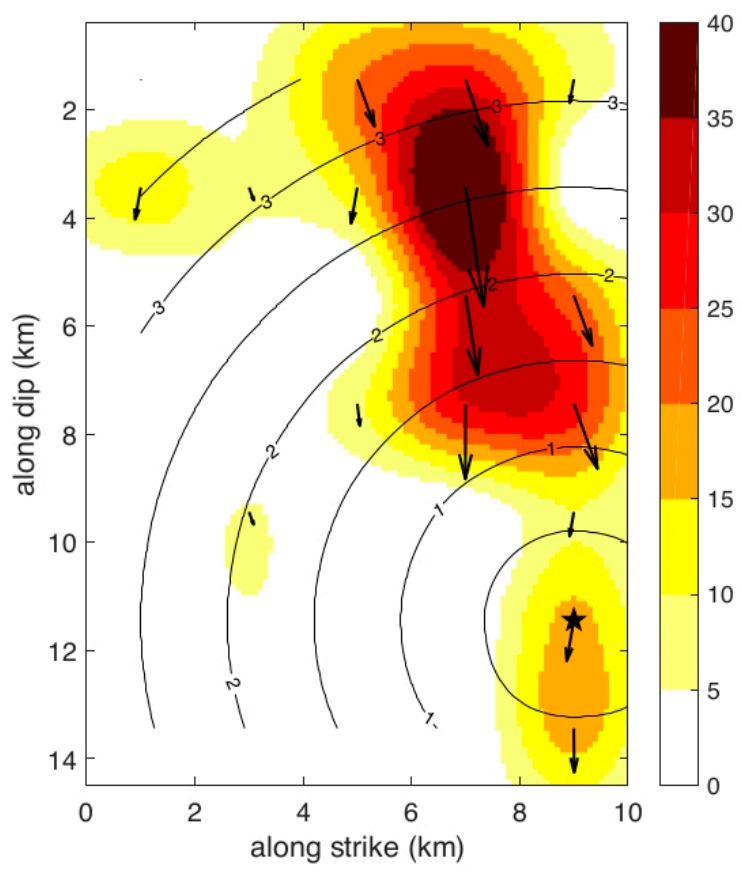

a)

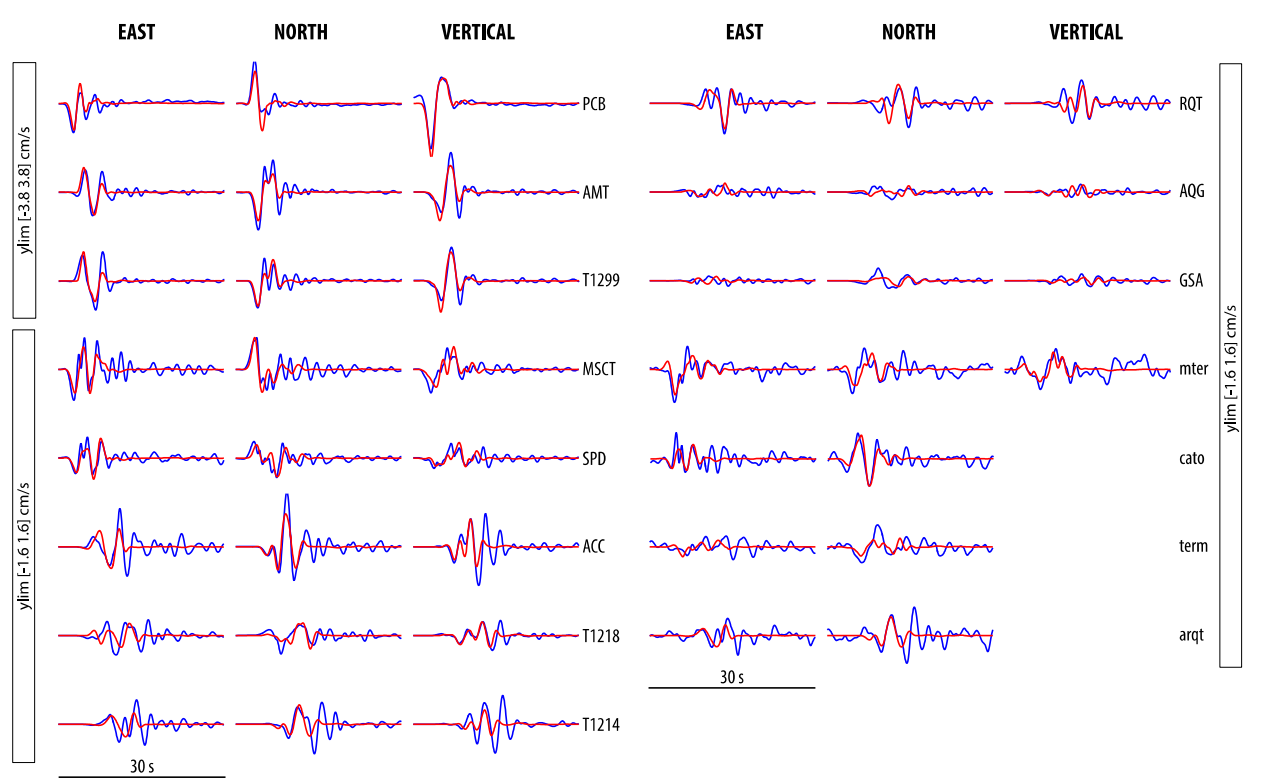

b)

Figure 7. Rupture model of the $\mathrm{M}_{\mathrm{W}} 5.5$ event. (a) Slip amplitudes are expressed in $\mathrm{cm}$ and rupture times in seconds (as shown by contour lines). The black arrows indicate the slip direction. The star represents the hypocenter. (b) Fit to the data: recorded strong-motion and HR-GPS data (blue lines) and synthetic ground velocity (red lines). See Figure $3 \mathrm{f}$ for station locations.

\subsubsection{The $\mathrm{M}_{\mathrm{W}}$ 5.4 Earthquake}

We determined the kinematic finite-fault model of the second major event of the sequence from the inversion of ground velocity time histories from 14 seismic stations. For this smaller-magnitude 
earthquake, the available HR-GPS signals were too noisy to be included in the inversion. In this case, the fault top reaches $\sim 3 \mathrm{~km}$ depth and the hypocentral depth is $9.71 \mathrm{~km}$. The best-fit rupture speed is $2.3 \mathrm{~km} / \mathrm{s}$ and the model is characterized by a constant rise time of $0.7 \mathrm{~s}$. The estimated seismic moment is equal to $1.76 \times 10^{17} \mathrm{Nm}$, corresponding to a $\mathrm{M}_{\mathrm{W}} 5.46$ seismic event. As with the kinematic model of the largest event of the sequence $\left(\mathrm{M}_{\mathrm{W}} 5.5\right)$, the most relevant feature of this model is up-dip rupture directivity, with a main slip patch (maximum slip $\sim 35 \mathrm{~cm}$ ) entirely located above the hypocenter (Figure 8). Finally, a smaller patch of slip (up to $\sim 20 \mathrm{~cm}$ of slip) is located westward from the hypocenter at deeper depths (Figure 8). The variance reduction is about $71 \%$ as shown by the fit of the synthetic seismograms with the observations (Figure 8).

a)

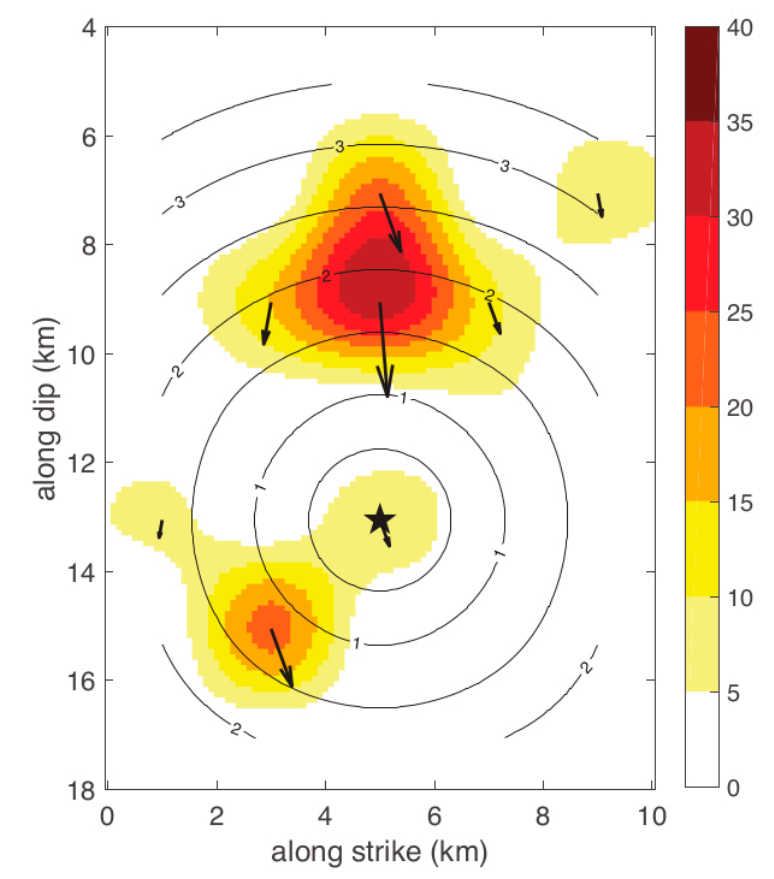

b)

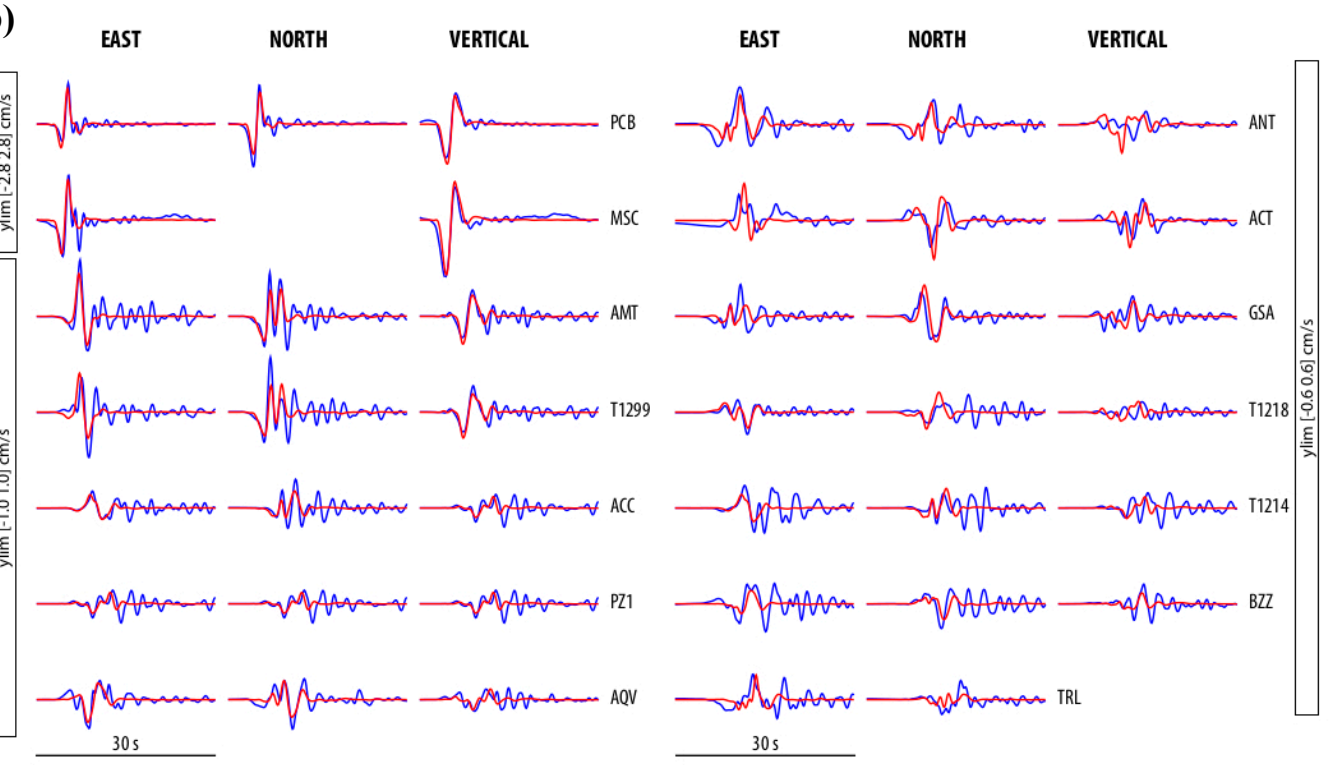

Figure 8. Rupture model of the $\mathrm{M}_{\mathrm{W}} 5.4$ event. (a) Slip amplitudes are expressed in $\mathrm{cm}$ and rupture times in seconds (as shown by contour lines). The black arrows indicate the slip direction. The star represents the hypocenter. (b) Fit to the data: recorded strong-motion (blue lines) and synthetic ground velocity (red lines). See Figure $3 \mathrm{f}$ for station locations. 


\subsection{Static Coulomb Stress Change}

Coseismic slip induces changes in static stress that may trigger subsequent earthquakes as well as patches of aseismic slip on adjacent faults and on unruptured portions of the causative seismogenic fault itself (e.g., [59,63-66]). To investigate the stress variation on the Campotosto seismogenic fault induced by the previous seismic events as well as the stress changes induced by the 18 January 2017 events, we calculated the static Coulomb stress changes on the Campotosto fault plane. Coulomb stress changes are computed using an effective friction coefficient of 0.4 , as is commonly used in stress interaction studies (e.g., $[67,68])$. We first calculated the change of Coulomb stress induced by the previous five events: the 6 April $2009 \mathrm{M}_{\mathrm{W}} 6.3$ L'Aquila [36], the 9 April $\mathrm{M}_{\mathrm{W}} 5.7$ Campotosto [36], the 24 August $2016 \mathrm{M}_{\mathrm{W}} 6.0$ Amatrice [12], the 26 October $\mathrm{M}_{\mathrm{W}} 5.9$ Visso [11] and the 30 October $2016 \mathrm{M}_{\mathrm{W}} 6.5$ Norcia earthquakes [17], respectively. The results indicate positive Coulomb stress on the Campotosto fault plane, between Amatrice and Campotosto (Figure 9), with largest values southeastward of Amatrice, where seismicity migrated from December 2016 until the occurrence of the 18 January 2017 earthquakes (blue circles in Figure 9). The four 18 January $M>5$ events then occurred on a portion of the fault positively stressed by the previous events (Figure 9).

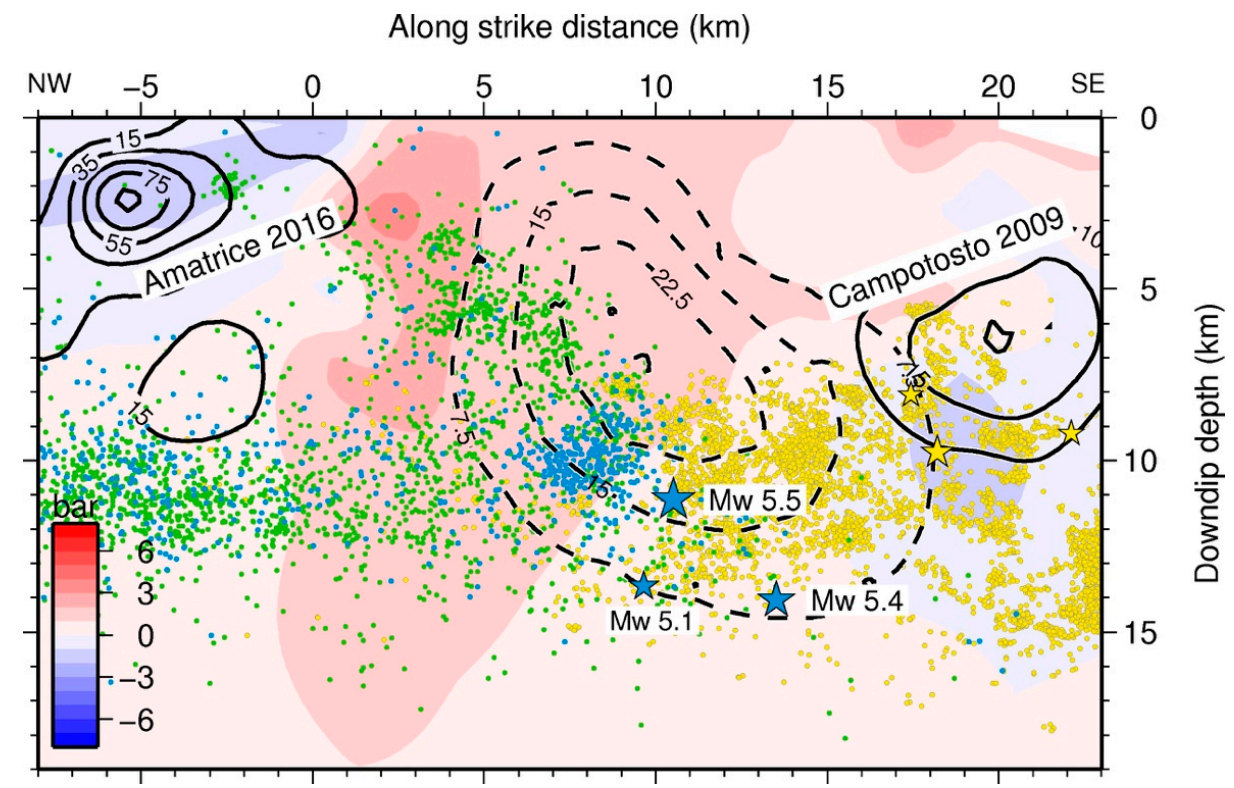

Figure 9. Change of Coulomb stress on the Campotosto fault plane before the occurrence of the 2017 seismic sequence resolved on the fault plane. The contouring (solid lines, in $\mathrm{cm}$ ) indicates the modeled slip distribution of the previous 2009 Campotosto and 24 August 2016 Amatrice earthquakes [12,36], respectively, projected on the Campotosto fault geometry used in this study, and the cumulative slip distribution of the 2017 sequence (dashed lines). The circles and stars represent the seismicity projected on the fault surface (within $2 \mathrm{~km}$ ): green circles are relocated aftershocks of the 2016-2017 central Italy seismic sequence between 24 August and 30 November 2016 [11]; blue circles are events between 1 December 2016 and 17 January 2017 [32]; yellow circles are relocated aftershocks of the 2009 seismic sequence [31]; the blue stars are the largest events of the 2017 Campotosto seismic sequence, while the yellow ones are the main events of the previous 2009 seismic sequence affecting the southern part of the Campotosto fault plane.

In a second step, we calculated the change of Coulomb stress from the cumulative effects of the previous sequences and from the events of the 18 January 2017 sequence. In this case, the area that slipped during the 2017 events appears characterized by strongly negative Coulomb stress change while the portions of the plane at the border show large stress increase. In particular, we find that significant stress increased in the upper portions of the Campotosto fault, between the 24 August 2016 Amatrice earthquake and the 2017 sequence, and between the 2009 and 2017 Campotosto sequences, 
exactly below the Campotosto lake (Figure 10). While numerous aftershocks occurred in the first area, the second area, located below the dam, was devoid of significant seismicity. Other areas of increased stress are the deep portions of the fault plane, below hypocentral depths (Figure 10).

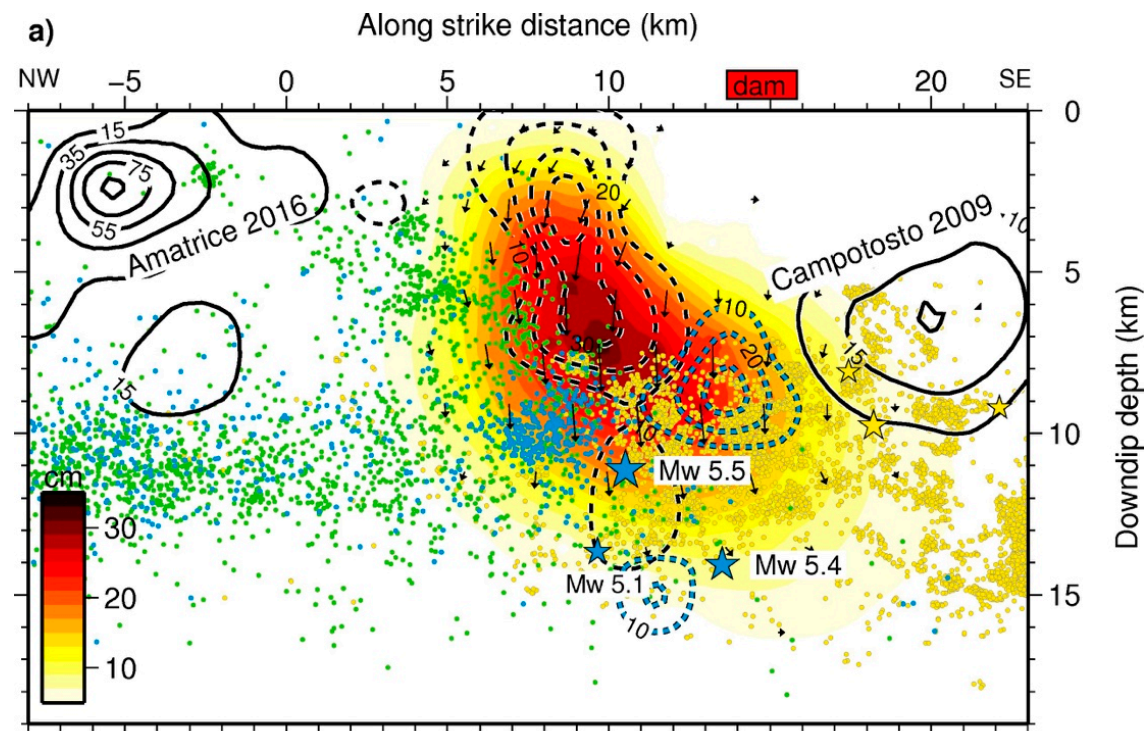

b)

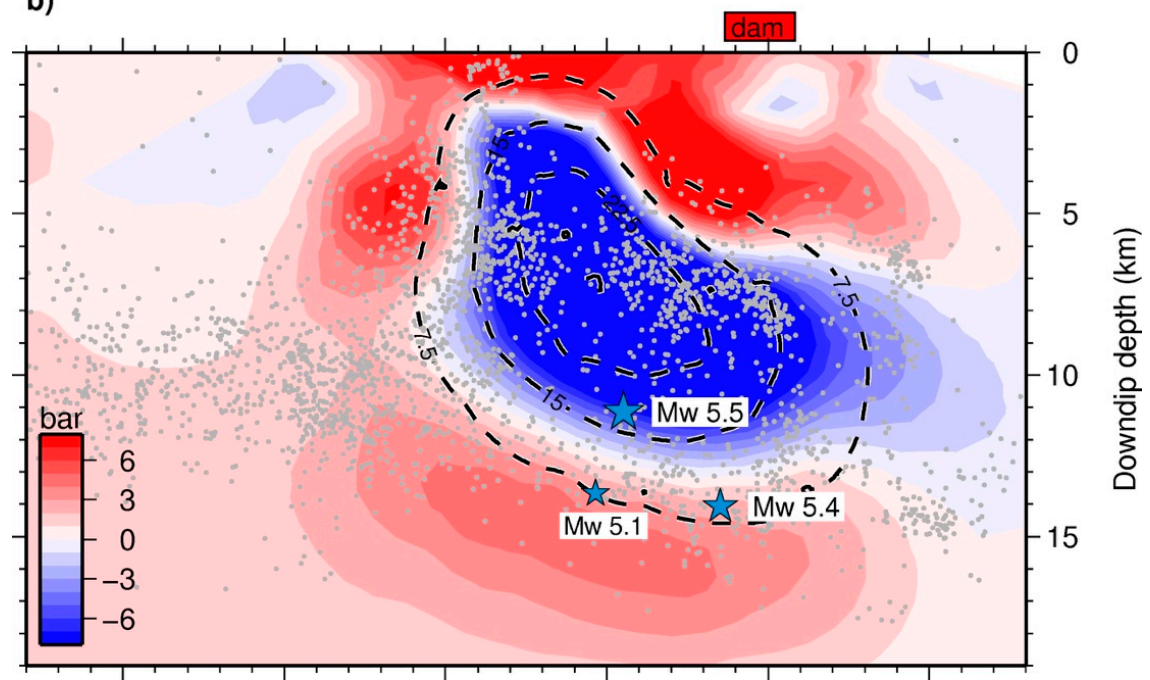

Figure 10. Slip distribution and Coulomb stress change on the Campotosto fault plane. (a) Cumulative slip distribution: the contouring (solid lines, in $\mathrm{cm}$ ) indicates the modeled slip distribution of the previous 2009 Campotosto and 24 August 2016 Amatrice earthquakes [12,36], respectively, projected on the Campotosto fault geometry used in this study, and the modeled slip distributions of the two largest events of the 2017 sequence, i.e., the $M_{W} 5.5$ earthquake (black dashed lines) and the $M_{W} 5.4$ seismic event (blue dashed lines). The circles and stars represent the seismicity projected on the fault surface (within $2 \mathrm{~km}$ ): green circles are relocated aftershocks of the 2016-2017 central Italy seismic sequence between 24 August and 30 November 2016 [11]; blue circles are events between 1 December 2016 and 17 January 2017 [32]; yellow circles are relocated aftershocks of the 2009 seismic sequence [31]; the blue stars are the largest events of the 2017 Campotosto seismic sequence, while the yellow ones are the main events of the previous 2009 seismic sequence affecting the southern part of the Campotosto fault plane. (b) Change of Coulomb stress resolved on the Campotosto fault (friction coefficient $=0.4$ ). The contouring (dashed lines, in $\mathrm{cm}$ ) indicates the cumulative slip distribution of the 2017 sequence. Gray circles are relocated aftershocks projected on the fault surface (within $2 \mathrm{~km}$ ) between 18 January and 30 June 2017 [32]. The blue stars are the largest events of the 2017 Campotosto seismic sequence. 


\section{Discussion}

The availability of high-quality geodetic and seismic data from the 18 January 2017 Campotosto seismic sequence allowed us to constrain the geometry of the causative fault, and to model the rupture history of the two largest events of the sequence, along with the cumulative slip distribution of the whole sequence. Our results improve the knowledge of the seismic source responsible for the 2017 earthquake sequence $[27,37]$, and helps unravelling the way in which the tectonic deformation is released by the Campotosto fault.

The 2017 Campotosto seismic sequence occurred on a $\sim 50^{\circ}$ SW-dipping and $\sim 150^{\circ}$ striking normal fault, in agreement with previous inversion of geodetic data [27,37]. This fault is well known by geological and paleoseismological studies (e.g., [21-25]). Rupture histories of the two largest events of the sequence show that the two largest shocks ruptured two distinct and adjacent portions of the Campotosto fault (Figure 10a). The $\mathrm{M}_{\mathrm{W}} 5.5$ event was characterized by a main slip patch up-dip from the hypocenter with a peak slip of about $50 \mathrm{~cm}$. The following $\mathrm{M}_{\mathrm{W}} 5.4$ earthquake was also characterized by significant slip up-dip from its hypocenter, but the slip in this case does not reach shallow depths (Figure 10a). The geodetically estimated cumulative slip distribution is almost the sum of the slip distributions of the two events. Increased slip at the edges of the seismically derived coseismic patches of slip (Figure 10a), suggesting that post-seismic deformation may have been triggered at the edges of the coseismic asperity where gradients of slip caused significant increase of shear stress on the unruptured portions of the fault. Figure 11 summarizes our geodetic and seismic results with respect to the position of the superficial expression of the exposed fault plane which bounds the western slope of Mt. Gorzano. It is worth noting that the strong-motion model predicts more surficial slip $(<1 \mathrm{~km})$ than the geodetic model, as seen by the different patterns of InSAR fringes near the surface trace of the fault (compare Figure 11a and 11b). As a matter of fact, the slip during the 18 January 2017 Campotosto sequence is mainly concentrated up-dip from the hypocenters of the largest shocks of the sequence, with significant slip extending at shallow depths $(<1-2 \mathrm{~km})$, challenging the hypothesis supporting lack of vertical continuity of the Campotosto fault $[39,40]$.

The seismic moment release calculated using our geodetic dataset for the cumulative 2017 sequence is $9.29 \times 10^{17} \mathrm{Nm}$, corresponding to an $\mathrm{M}_{\mathrm{W}} \sim 6$ earthquake, within the range obtained in the previous studies $[27,37]$. The cumulative geodetic inversion images a main slip patch along the Campotosto fault, extending upward from the hypocenter of the main $\mathrm{M}_{\mathrm{W}} 5.5$ event and reaching a maximum slip value of around $40 \mathrm{~cm}$. The kinematic finite-fault inversions of the two largest events of the sequence yield a total seismic moment of $4.57 \times 10^{17} \mathrm{Nm}$, equivalent to a $\mathrm{M}_{\mathrm{W}} 5.7$ earthquake and, corresponding to the $49 \%$ of the total moment released calculated geodetically. Part of this difference should be ascribed to the other two main events on the 18 January (the $\mathrm{M}_{\mathrm{W}} 5.1$ and 5.0 earthquakes) corresponding to a moment release of about $1.05 \times 10^{17} \mathrm{Nm}$, and to lower seismicity $(\mathrm{M}<5)$ in the time span of the geodetic observations. In particular, between 18 January and 11 February 2017, 27 earthquakes with moment magnitude between 3.5 and 4.9 occurred in the epicentral area, releasing an additional seismic moment of about $0.4 \times 10^{17} \mathrm{Nm}$. The balance between cumulative coseismic $(6.01 \times$ $\left.10^{17} \mathrm{Nm}\right)$ and total co- and post-seismic geodetic $\left(9.29 \times 10^{17} \mathrm{Nm}\right)$ moment release on the Campotosto fault suggests that a fraction $(\sim 35 \%)$ of the overall deformation occurring during and after the 18 January 2017 Campotosto seismic sequence can be attributable to aseismic processes. This amount of aseismic deformation is similar to the value $(\sim 40 \%)$ obtained from the comparison of the seismically released moment and the geodetically released moment obtained from the joint inversion of InSAR, GPS and levelling data of the April 2009 Campotosto seismic sequence [36]. 

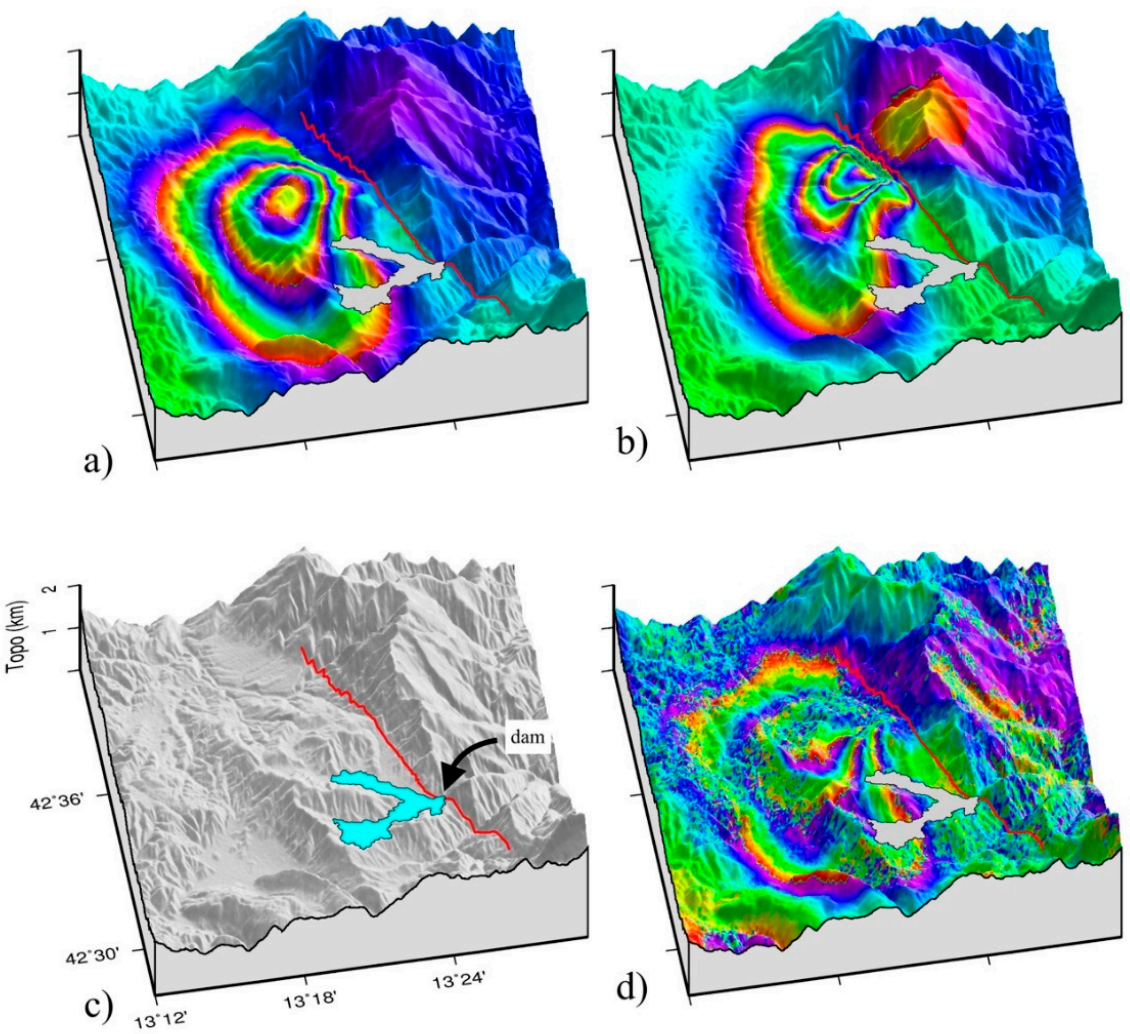

Figure 11. 3-D view from S-SE of the synthetic and observed LOS deformation fields plotted with the topography of the area. Synthetic interferograms computed by means of the geodetic model (a) and of the strong-motion model (b), compared with the surficial expression of the Campotosto fault (red line) and the Campotosto lake (c), and with the observed interferogram (d).

Previous studies [34-36] have shown that during the 2009 Campotosto earthquake swarm, the fault ruptured only the southern portion of its total length with very little to no movements occurring between 0 and $5 \mathrm{~km}$ depth. On the other hand, during the 2017 Campotosto seismic sequence, the fault ruptured the northern area of the fault plane, with significant slip extending up to very shallow depths $(<2 \mathrm{~km}$, Figure 10). We find that the two distributions of slip are complementary along the fault, suggesting the activation of different portions of the seismogenic fault during the two recent seismic sequences and the presence of an unruptured area between these two portions. In this context, it is important for hazard assessment in the Campotosto area to identify the contribution of these moderate-size earthquake sequences and/or the redistribution of stress loads from neighboring faults that may have contributed to stress changes following the seismic events. We use the Coulomb stress changes as an indicator, even if simplistic, to examine the interaction between the recent earthquakes that struck central Italy and the potential state of stress of the unruptured portions of the Campotosto fault. Although the actual state of stress of Campotosto fault is difficult to estimate (as it depends on many unknown factors, e.g., non-uniform distribution of pre-stress, variation of frictional properties), we find increased Coulomb stress on the Campotosto fault due to previous seismic sequences that affected the central Apennines in recent decades (Figure 9). The occurrence of the 18 January earthquakes caused a further increase of stress in the upper central portion of the Campotosto fault, just below the Campotosto lake and on the deeper portions of the fault, below hypocentral depths (Figure 10), in agreement with previous studies [69] that suggested that a large part of the Campotosto fault was positively stressed after the 18 January earthquakes.

The upper part of the Campotosto fault that remained unruptured areas during the 2009 and 2016-2017 should be considered for future hazard assessment. The area just southeastward of Amatrice could represent either a structural separation between the two hypothesized kinematically independent 
Amatrice and the Campotosto faults [27] or an unbroken portion of a single longer fault including both the Campotosto and the Amatrice segments [25]. It is worth mentioning that this area experienced a large number of aftershocks following the 24 August Amatrice earthquake (Figure 10). By the frictional point of view; the parts of the Campotosto fault positively stressed by the 2009 and 2017 seismic sequence; may be characterized by velocity strengthening behavior [70] releasing stress increases with aseismic slow deformation. Alternatively; these parts of the fault may be velocity weakening and represent an area that remained locked and acted as a barrier during the recent seismic sequences. Depending on the heterogeneous condition of stress on the fault; the second hypothesis allows the possibility that the unbroken area may become closer to failure; and rupture in a future earthquake(s). The shallow $(<5 \mathrm{~km})$ depth of this unbroken area reduces the possibility of nucleating destructive earthquakes $(M>6)$. On the other hand; we cannot exclude that a large earthquake nucleating at deeper depths could either (1) rupture across the part of the fault that already slipped during the previous moderate-size earthquake sequences, or (2) could stop its propagation; depending; for example; on the dynamic stress condition on the fault plane.

Finally, while the recent moderate events occurring from 2009 to 2017 released accumulated strain through a series of moderate $\mathrm{M} \approx 5$ events, there is paleoseismological evidence of large surface-rupturing events ( $\mathrm{M}>6.5$, e.g., [21,22]). We suggest, therefore, that the Campotosto fault releases accumulated tectonic strain through a wide range of magnitudes and a very heterogeneous (seismic vs aseismic) behavior.

\section{Conclusions}

Despite moderate magnitudes of the earthquakes, the 2017 Campotosto sequence resulted in a well detectable surface displacement field by both the radar satellites and GPS observations. In this study, we used InSAR interferograms and GPS data to constrain the causative fault and the cumulative slip distribution associated with the 18 January 2017 Campotosto seismic sequence. In addition, near-source strong-motion and high-sampling rate GPS data allowed us to retrieve the rupture history of the two largest ( $\mathrm{M}_{\mathrm{W}} 5.5$ and 5.4) events of the sequence, giving insights into the evaluation of the seismic $v$ s aseismic release processes.

The 18 January 2017 Campotosto sequence was caused by the rupture of a segment of the Mts. Laga $\left(\sim 50^{\circ}\right)$ SW-dipping normal fault, outcropping on the western flank of the Mt. Gorzano (i.e., the Campotosto fault). The consistency of slip distributions obtained from the geodetic and waveform inversions confirm that slip occurred at shallow depths, up-dip from the hypocenters of the main $\left(\mathrm{M}_{\mathrm{W}}\right.$ $>5$ ) events of the sequence. Shallow slip (up to $<2 \mathrm{~km}$ depth) is required to explain both geodetic and seismic data, revealing a vertical continuity of the causative Campotosto fault from hypocentral depths to the shallow portion of the source fault. The total seismic moment release calculated for the cumulative sequence is $35 \%$ larger than the seismic release implying some component of aseismic deformation. This behavior is similar to what was observed during the previous 2009 Campotosto moderate events seismic sequence.

The complementary spatial pattern between the 2009 and 2017 slip distributions implies the rupture of two distinct portions of the Campotosto fault, and shows that the upper central part of the seismogenic fault remained unruptured and was positively stressed by an increase of Coulomb stress. The recent moderate-size seismic sequences, integrated with paleoseismological evidence of $M>6.5$ earthquakes, suggest a heterogeneous behavior of the Campotosto normal fault. Therefore, defining the maximum potential length and slip associated for a given fault may be not sufficient to characterize the seismic hazard in a given region. A more complex picture emerges when detailed seismic and geodetic observations are available, such as in the present study, showing a heterogeneous pattern of seismic and aseismic slip, which may depend on rheological and dynamic conditions as well as on available stress levels on the fault surface. The definition of such heterogeneous slip behavior is therefore critical for evaluating the seismic hazards posed by an active fault. 
Supplementary Materials: The following are available online at http://www.mdpi.com/2072-4292/11/12/1482/s1, Figure S1: Fault parameter uncertainties and trade-offs between model parameters. Figure S2: Fit to the GPS data with the best-fit uniform slip model. Figure S3: Trade-off curves between RMS data and model roughness. Figure S4: Relationship between RMS data reduction and relative weighting factors. Figure S5: Fit to the horizontal components of GPS data as a function of the assumed fault top depth. Figure S6: Fit to the vertical component of GPS data as a function of the assumed fault top depth. Figure S7: trade-off curves between RMS data reduction and the assumed fault top depth.

Author Contributions: Conceptualization, N.D.; Data curation, N.D., L.S., E.T., C.B., A.A., R.G., S.C., P.G. and M.M.; Formal analysis, D.C., L.S. and E.T.; Investigation, D.C., L.S. and E.T.; Methodology, D.C., L.S. and E.T.; Software, D.C., N.D., L.S., E.T., C.B., A.A., R.G., S.C., P.G. and M.M.; Supervision, N.D.; Visualization, D.C., N.D., L.S., E.T. and C.B.; Writing - original draft, D.C.; Writing - review and editing, N.D., L.S., E.T., C.B., A.A., R.G., S.C., P.G. and M.M.

Funding: This research received no external funding.

Acknowledgments: We would like to thank the Editor, and three anonymous reviewers fort their constructive suggestions, which helped to improve the manuscript. Most of the figures were created using the Generic Mapping Tools (GMT) software. As far as authors of the Civil Protection Department (R.G. and M.M.), the views and conclusions contained in this paper are those of the authors, and they should not be interpreted as necessarily representing official policies, either expressed or implied, of the Italian Government. The InSAR interferograms, GPS and strong-motion data can be obtained by contacting the corresponding author (daniele.cheloni@ingv.it). The slip models are released in the online database of finite-fault rupture models http://equake-rc.info/srcmod/.

Conflicts of Interest: The authors declare no conflict of interest.

\section{References}

1. Peng, Z.; Gomber, J. An integrated perspective of the continuum between earthquakes and slow-slip phenomena. Nat. Geosci. 2010, 3, 599-607. [CrossRef]

2. Wei, S.; Helmberger, D.; Owen, S.; Graves, R.W.; Hudnut, K.W.; Fielding, E.J. Complementary slip distributions of the largest earthquakes in the 2012 Brawley swarm, Imperial Valley, California. Geophys. Res. Lett. 2013, 82, 847-852. [CrossRef]

3. Avouac, J.-P. From geodetic imaging of seismic and aseismic fault slip to dynamic modeling of the seismic cycle. Annu. Rev. Earth Planet. Sci. 2015, 43, 233-271. [CrossRef]

4. Villegas-Lanza, J.C.; Nocquet, J.-M.; Rolandone, F.; Vallée, M.; Tavera, H.; Bondoux, F.; Tran, T.; Martin, X.; Chlieh, M. A mixed seismic-aseismic stress release episode in the Andean subduction zone. Nat. Geosci. 2016, 9, 150-154. [CrossRef]

5. Kyriakopoulos, C.; Chini, M.; Bignami, C.; Stramondo, S.; Ganas, A.; Kolligri, M.; Moshou, A. Monthly migration of a tectonic seismic swarm detected by DInSAR: Southwest Peloponnese, Greece. Geophys. J. Int. 2013, 194, 1302-1309. [CrossRef]

6. Cheloni, D.; D’Agostino, N.; Selvaggi, G.; Avallone, A.; Fornaro, G.; Giuliani, R.; Reale, D.; Sansosti, E.; Tizzani, P. Aseismic transient during the 2010-2014 seismic swarm: Evidence for longer recurrence of $\mathrm{M} \geq$ 6.5 earthquakes in the Pollino gap (Southern Italy)? Sci. Rep. 2017, 576, 1-10. [CrossRef]

7. Gualandi, A.; Nichele, C.; Serpelloni, E.; Chiaraluce, L.; Anderlini, L.; Latorre, D.; Belardinelli, M.E.; Avouac, J.-P. Aseismic deformation associated with an earthquake swarm in the northern Apennines (Italy). Geophys. Res. Lett. 2017, 16, 7706-7714. [CrossRef]

8. Page, M.; Felzer, K. Southern San Andreas Fault seismicity is consistent with the Gutunberg-Richter magnitude frequency distribution. Bull. Seismol. Soc. Am. 2015, 105, 2070-2080. [CrossRef]

9. Parsons, T.; Geist, E.L. Is there basis for preferring characteristic earthquakes over Gutenberg-Richter distributions on individual faults in probabilistic earthquake forecasting? Bull. Seismol. Soc. Am. 2009, 99, 2012-2019. [CrossRef]

10. Schwartz, D.P. Do large earthquakes on faults follow a Gutenberg-Richter or characteristic distribution? Seismol. Res. Lett. 2010, 81, 331.

11. Chiaraluce, L.; Di Stefano, R.; Tinti, E.; Scognamiglio, L.; Michele, M.; Casarotti, E.; Cattaneo, M.; De Gori, P.; Chiarabba, C.; Monachesi, G.; et al. The 2016 Central Italy Seismic Sequence: A First Look at the Mainshocks, Aftershocks and Source Models. Seismol. Res. Lett. 2017, 88, 757-771. [CrossRef] 
12. Tinti, E.; Scognamiglio, L.; Michelini, A.; Cocco, M. Slip heterogeneity and directivity of the $\mathrm{M}_{\mathrm{L}} 6.0,2016$, Amatrice earthquake estimated with rapid finite-fault inversion. Geophys. Res. Lett. 2016, 43, 10745-10752. [CrossRef]

13. Cheloni, D.; de Novellis, V.; Albano, M.; Antonioli, A.; Anzidei, M.; Atzori, S.; Avallone, A.; Bignami, C.; Bonano, M.; Calcaterra, S. Geodetic model of the 2016 Central Italy earthquake sequence inferred from InSAR and GPS data. Geophys. Res. Lett. 2017, 44, 6778-6787. [CrossRef]

14. Walters, R.J.; Gregory, L.C.; Wedmore, L.N.J.; Craig, T.J.; McCaffrey, K.; Wilkinson, M.; Chen, J.; Li, Z.; Elliott, J.R.; Iezzi, H.; et al. Dual control of fault interactions on stop-start rupture in the 2016 Central Italy seismic sequence. Earth Planet. Sci. Lett. 2018, 500. [CrossRef]

15. Cheloni, D.; Falcucci, E.; Gori, S. Half-graben rupture geometry of the 30 October 2016 Mw 6.6 Mt. Vettore-Mt. Bove earthquake, central Italy. J. Geophys. Res. 2019, 124. [CrossRef]

16. Pizzi, A.; Di Domenica, A.; Gallovic, F.; Luzi, L.; Puglia, R. Fault Segmentation as Constraint to the Occurrence of the Main Shocks of the 2016 Central Italy Seismic Sequence. Tectonics 2017, 36. [CrossRef]

17. Scognamiglio, L.; Tinti, E.; Casarotti, E.; Pucci, S.; Villani, F.; Cocco, M.; Magnoni, F.; Michelini, A.; Dreeger, D. Complex fault geometry and rupture dynamics of the $\mathrm{M}_{\mathrm{W}} 6.5,2016$, October 30th central Italy earthquake. J. Geophys. Res. 2018, 123. [CrossRef]

18. Civico, R.; Pucci, S.; Villani, F.; Pizzimenti, L.; De Martini, P.M.; Nappi, R. The Open EMERGEo Working Group. Surface ruptures following the 30 October $\mathrm{M}_{\mathrm{W}} 6.5$ Norcia earthquake, central Italy. J. Maps 2018, 14, 151-160. [CrossRef]

19. Gori, S.; Falcucci, E.; Galadini, F.; Zimmaro, P.; Pizzi, A.; Kayen, R.E.; Lingwall, B.N.; Moro, M.; Saroli, M.; Fubelli, G.; et al. Surface Faulting Caused by the 2016 Central Italy Seismic Sequence: Field Mapping and LiDAR/UAV Imaging. Earthq. Spectra 2018, 34, 1585-1610. [CrossRef]

20. Improta, L.; Latorre, D.; Margheriti, L.; Nardi, A.; Marchetti, A.; Lombardi, A.M.; Castello, B.; Villani, F.; Ciaccio, M.G.; Mele, F.M.; et al. Multi-segment rupture of the 2016 Amatrice-Visso-Norcia seismic sequence (central Italy) constrained by the first high-quality catalog of Early Aftershocks. Sci. Rep. 2019, 9, 6921. [CrossRef]

21. Galadini, F.; Galli, P. Paleoseismology of silent faults in the Central Apennines (Italy): The Mt. Vettore and Laga Mts. faults. Ann. Geophys. 2003, 815-836. [CrossRef]

22. Galli, P.; Galadini, F.; Pantosti, D. Twenty years of paleoseismology in Italy. Earth-Sci. Rev. 2008, 88, 89-117. [CrossRef]

23. Blumetti, A.M.; Dramis, F.; Michetti, A.M. Fault-generated mountain fronts in the central Apennines (Central Italy): Geomorphological features and seismotectonic implications. Earth Surf. Proc. Land 1993, 18, $203-223$. [CrossRef]

24. Boncio, P.; Lavecchia, G.; Milana, G.; Rozzi, B. Seismogenesis in Central Apennines, Italy: An integrated analysis of minor earthquake sequences and structural data in the Amatrice-Campotosto area. Ann. Geophys. 2004, 47, 1723-1742. [CrossRef]

25. Lavecchia, G.; Ferrarini, F.; Brozzetti, F.; De Nardis, R.; Boncio, P.; Chiaraluce, L. From surface geology to aftershock analysis: Constraints on the geometry of the L'Aquila 2009 seismogenic fault system. Ital. J. Geosci. 2012, 131, 330-347. [CrossRef]

26. Falcucci, E.; Gori, S.; Galadini, F.; Fubelli, G.; Moro, M.; Saroli, M. Active faults in the epicentral and mesoseismal Ml 24, 2016 Amatrice earthquake region, central Italy. Methodological and seismotectonics issues. Ann. Geophys. 2016, 59. [CrossRef]

27. Falcucci, E.; Gori, S.; Bignami, C.; Pietrantonio, G.; Melini, D.; Moro, M.; Saroli, M.; Galadini, F. The Campotosto Seismic Gap in Between the 2009 and 2016-2017 Seismic Sequences of Central Italy and the Role of Inherited Lithospheric Faults in Regional Seismotectonic Settings. Tectonics 2018, 37. [CrossRef]

28. Boncio, P.; Lavecchia, G.; Pace, B. Defining model of 3D seismogenic sources for seismic hazard assessment applications: The case of central Apennines (Italy). J. Seismol. 2004, 8, 407-425. [CrossRef]

29. Bigi, G.; Cosentino, D.; Parotto, M.; Sartoti, R.; Scandone, P. Structural Model of Italy, Scale 1:500.000; Consiglio Nazionale delle Ricerche: Rome, Italy, 1990; p. 193.

30. Pizzi, A.; Galadini, F. Pre-existing cross-structure and active faults segmentation in the central Apennines (Italy). Tectonophysics 2009, 476. [CrossRef] 
31. Valoroso, L.; Chiaraluce, L.; Piccinini, D.; Di Stefano, R.; Schaff, D.; Waldhauser, F. Radiography of a normal fault system by 64,000 high-precision earthquake locations: The 2009 L'Aquila (central Italy) case study. J. Geophys. Res. 2013, 118, 1156-1176. [CrossRef]

32. Chiarabba, C.; De Gori, P.; Catteneo, M.; Spallarossa, D.; Segou, M. Faults geometry and the role of fluids in the 2016-2017 Central Italy seismic sequence. Geophys. Res. Lett. 2018, 45, 6963-6971. [CrossRef]

33. Rovida, A.; Locati, M.; Camassi, R.; Lolli, B.; Gasperini, P. CPTI15, the 2015 Version of the Parametric Catalogue of Italian Earthquakes; Istituto Nazionale di Geofisica e Vulcanologia: Roma, Italy, 2016. [CrossRef]

34. Chiaraluce, L.; Valoroso, L.; Piccinini, D.; Di Stefano, R.; De Gori, P. Anatomy of the 2009 L'Aquila normal fault system (Central Italy) imaged by high resolution foreshock and aftershock locations. J. Geophys. Res. 2011, 116. [CrossRef]

35. Malagnini, L.; Lucente, F.P.; De Gori, P.; Akinci, A.; Munafò, I. Control of pore fluid diffusion on fault failure mode: Insights from the 2009 L'Aquila seismic sequence. J. Geophys. Res. 2012, 117. [CrossRef]

36. Cheloni, D.; Giuliani, R.; D'Anastasio, E.; Atzori, S.; Walters, R.J.; Bonci, L.; D'Agostino, N.; Mattone, M.; Calcaterra, S.; Gambino, P.; et al. Coseismic and post-seismic slip of the 2009 L'Aquila (central Italy) $\mathrm{M}_{\mathrm{W}}$ 6.3 earthquake and implications for seismic potential along the Campotosto fault from joint inversion of high-precision levelling, InSAR and GPS data. Tectonophysics 2014, 622, 168-185. [CrossRef]

37. Xu, G.; Xu, C.; Wen, Y.; Jiang, G. Source Parameters of the 2016-2017 Central Italy Earthquake Sequence from the Sentinel-1, ALOS-2 and GPS Data. Remote Sens. 2017, 9, 1182. [CrossRef]

38. D'Agostino, N. Complete seismic release of tectonics strain and earthquake recurrence in the Apennines (Italy). Geophys. Res. Lett. 2014, 41, 115-162. [CrossRef]

39. Bigi, S.; Casero, P.; Chiarabba, C.; Di Bucci, D. Contrasting surface active faults and deep seismogenic sources unveiled by the 2009 L'Aquila earthquake sequence (Italy). Terra Nova 2012, 25. [CrossRef]

40. Buttinelli, M.; Pezzo, G.; Valoroso, L.; De Gori, P.; Chiarabba, C. Tectonics Inversions, Fault Segmentations, and Triggering Mechanisms in the Central Apennines Normal Fault System: Insights from High-Resolution Velocity Models. Tectonics 2018, 37, 4135-4149. [CrossRef]

41. Zebker, H.A.; Rosen, P.A.; Goldstein, R.M.; Gabriel, A.; Werner, C.L. On the derivation of coseismic displacement fields using differential radar interferometry: The Landers earthquake. J. Geophys. Res. 1994, 99, 19617-19634. [CrossRef]

42. Farr, T.G.; Rosen, P.A.; Caro, E.; Crippen, R.; Duren, R.; Hensly, S.; Kobrik, M.; Paller, M.; Rodriguez, E.; Roth, L.; et al. The Shuttle Radar Topography Mission. Rev. Geophys. 2007, 45. [CrossRef]

43. Goldstein, R.M.; Werner, C.L. Radar interferograms filtering for geophysical appplications. Geophys. Res. Lett. 1998, 25, 4035-4038. [CrossRef]

44. Costantini, M. A novel phase unwrapping method based on network programming. IEEE Trans. Geosci. Remote Sens. 1998, 36, 813-821. [CrossRef]

45. Surace, L. La nuova rete geodetica nazionale IGM95: Risultati e prospettive di utilizzazione. Boll. Geod. Sci. Affini 1997, 56, 358-378.

46. Dach, R.; Hugentobler, U.; Fridez, P.; Meindl, M. Bernese GPS Software Version 5.0; Astronomical Institute, University of Bern: Bern, Switzerland, 2007.

47. Bohm, J.; Niell, A.; Tregoning, P.; Schuh, H. Global Mapping Function (GMF): A new empirical mapping function based on numerical weather model data. Geophys. Res. Lett. 2006, 33. [CrossRef]

48. Michelini, A.; Margheriti, L.; Cattaneo, M.; Cecere, G.; D'Anna, G.; Delladio, A.; Moretti, M.; Pintore, S.; Amato, A.; Basili, A.; et al. The Italian Seismic Network and the earthquake and tsunami monitoring and surveillance systems. Adv. Geosci. 2016, 43, 31-38. [CrossRef]

49. Moretti, M.; Pondrelli, S.; Margheriti, L.; Abruzzese, L.; Anselmi, M.; Arroucau, P.; Baccheschi, P.; Baptie, B.; Bonadio, R.; Bono, A.; et al. SISMIKO: Emergency network deployment and data sharing for the 2016 central Italy seismic sequence. Ann. Geophys. 2016, 59. [CrossRef]

50. Bertiger, W.; Desai, S.D.; Haines, B.; Harvey, N.; Moore, A.W.; Owen, S.; Weiss, J.P. Single receiver phase ambiguity resolution with GPS data. J. Geod. 2010, 84, 327-337. [CrossRef]

51. Avallone, A.; Latorre, D.; Serpelloni, E.; Cavaliere, A.; Herrero, A.; Cecere, G.; D'Agostino, N.; D’Ambrosio, C.; Devoti, R.; Giuliani, R.; et al. Coseismic displacement waveforms for the 2016 August 24 Mw 6.0 Amatrice earthquake (central Italy) carried out from High-Rate GPS data. Ann. Geophys. 2016, 59. [CrossRef]

52. Choi, K.; Bilich, A.; Larson, K.M.; Axelrad, P. Modified sidereal filtering: Implications for high-rate GPS positioning. Geophys. Res. Lett. 2004, 31. [CrossRef] 
53. Widowinski, S.; Bock, Y.; Zhang, J.; Fang, P.; Genrich, J. Southern California permanent GPS geodetic array: Spatial filtering of daily positions for estimating coseismic and postseismic displacements induced by the 1992 Landers earthquake. J. Geophys. Res. 1987, 102, 18057-18070. [CrossRef]

54. Okada, Y. Surface deformation due to shear and tensile faults in a half-space. Bull. Seism. Soc. Am. 1985, 75, 1135-1154.

55. Cheloni, D.; D'Agostino, N.; D’Anastasio, E.; Avallone, A.; Mantenuto, S.; Giuliani, R.; Mattone, M.; Calcaterra, S.; Gambino, P.; Dominici, D.; et al. Coseismic and initial post-seismic slip of the $2009 \mathrm{M}_{\mathrm{W}} 6.3$ L'Aquila earthquake, Italy, from GPS measurements. Geophys. J. Int. 2010, 181, 1539-1546. [CrossRef]

56. Avallone, A.; Cirella, A.; Cheloni, D.; Tolomei, C.; Theodoulidis, N.; Piatanesi, A.; Briole, P.; Ganas, A. Near-source high-rate GPS, strong motion and InSAR observations to image the 2015 Lefkada (Greece) Earthquake rupture history. Sci. Rep. 2018, 7. [CrossRef] [PubMed]

57. Corana, A.; Marchesi, M.; Martini, C.; Ridella, S. Minimizing multimodal functions of continuous variables with the "Simulated Annealing" algorithm. ACM Trans. Math. Softw. 1987, 13, 262-280. [CrossRef]

58. Press, W.H.; Teukolsky, S.A.; Vetterling, W.T.; Flannery, B.P. Numerical Recipes in C: The Art of Scientific Computing, 2nd ed.; Cambridge University Press: Cambridge, UK, 1992; pp. 262-280.

59. Cheloni, D.; Giuliani, R.; D'Agostino, N.; Mattone, M.; Bonano, M.; Fornaro, G.; Lanari, R.; Reale, D.; Atzori, S. New insights into fault activation and stress transfer between en echelon thrusts: The 2012 Emilia, Northern Italy, earthquake sequence. J. Geophys. Res. 2016, 121. [CrossRef]

60. Lohman, R.B.; Simons, M. Some thoughts on the use of InSAR data to constrain models of surface deformation: Noise structure and data downsampling. Geochem. Geophys. Geosyst. 2005, 6, Q01007. [CrossRef]

61. Dreger, D.S.; Gee, L.; Lombard, P.; Murray, M.H.; Romanowicz, B. Rapid finite-source analysis and near-field strong ground motions: Application to the $2003 \mathrm{M}_{\mathrm{W}} 6.5$ San Simeon and $2004 \mathrm{M}_{\mathrm{W}} 6.0$ Parkfield earthquakes. Seismol. Res. Lett. 2005, 76, 40-48. [CrossRef]

62. Herrmann, R.B.; Malagnini, L.; Munafò, I. Regional moment tensor of the 2009 L'Aquila earthquake sequence. Bull. Seismol. Soc. Am. 2011, 101, 975-993. [CrossRef]

63. Lin, J.; Stein, R.S. Stress triggering in thrust and subduction earthquakes, and stress interaction between the southern San Andreas and nearby thrust and strike-slip faults. J. Geophys. Res. 2004, 109, B02303. [CrossRef]

64. Perfettini, H.; Avouac, P. Modeling afterslip and aftershocks following the 1992 Landers earthquake. J. Geophys. Res. 2007, 112, B07409. [CrossRef]

65. Hsu, Y.J.; Avouac, J.P.; Yu, S.B.; Chang, C.H.; Wu, Y.M.; Woessner, J. Spatio-temporal slip, and stress level on the faults within the western foothills of Taiwan: Implication for fault frictional properties. Pure Appl. Geophys. 2009, 166, 1853-1884. [CrossRef]

66. King, G.C.P.; Stein, R.S.; Lin, J. Static stress changes and the triggering of earthquakes. Bull. Seismol. Soc. Am. 1994, 84, 935-953.

67. Freed, T.G. Earthquake triggering by static, dynamic, and post-seismic stress transfer. Annu. Rev. Earth Planet Sci. 2005, 33, 335-367. [CrossRef]

68. Ryder, I.; Burgmann, R.; Fielding, E. Static stress interactions in extensional earthquake sequences: An example from the South Lunggar Rift, Tibet. J. Geophys. Res. 2012, 117. [CrossRef]

69. Mildon, Z.K.; Roberts, G.P.; Faure Walker, J.P.; Iezzi, F. Coulomb stress transfer and fault interaction over millennia on non-planar active normal faults: The Mw 6.5-5.0 seismic sequence of 2016-2017, central Italy. Geophys. J. Int. 2017, 210, 1206-1218. [CrossRef]

70. Boatwright, J.; Cocco, M. Frictional constraints on crustal faulting. J. Geophys. Res. 1996, 101, 13895-13909. [CrossRef]

(C) 2019 by the authors. Licensee MDPI, Basel, Switzerland. This article is an open access article distributed under the terms and conditions of the Creative Commons Attribution (CC BY) license (http://creativecommons.org/licenses/by/4.0/). 